\title{
A Thermodynamic Model for Redox-Dependent Binding of Carbon Monoxide at Site-Differentiated, High Spin Iron Clusters
}

Charles H. Arnett, Matthew J. Chalkley, and Theodor Agapie

J. Am. Chem. Soc., Just Accepted Manuscript • Publication Date (Web): 28 Mar 2018

Downloaded from http://pubs.acs.org on March 28, 2018

\section{Just Accepted}

"Just Accepted" manuscripts have been peer-reviewed and accepted for publication. They are posted online prior to technical editing, formatting for publication and author proofing. The American Chemical Society provides "Just Accepted" as a service to the research community to expedite the dissemination of scientific material as soon as possible after acceptance. "Just Accepted" manuscripts appear in full in PDF format accompanied by an HTML abstract. "Just Accepted" manuscripts have been fully peer reviewed, but should not be considered the official version of record. They are citable by the Digital Object Identifier (DOI®). "Just Accepted" is an optional service offered to authors. Therefore, the "Just Accepted" Web site may not include all articles that will be published in the journal. After a manuscript is technically edited and formatted, it will be removed from the "Just Accepted" Web site and published as an ASAP article. Note that technical editing may introduce minor changes to the manuscript text and/or graphics which could affect content, and all legal disclaimers and ethical guidelines that apply to the journal pertain. ACS cannot be held responsible for errors or consequences arising from the use of information contained in these "Just Accepted" manuscripts. 


\section{INTRODUCTION}

The Mo-nitrogenase enzyme mediates the multielectron reductions of $\mathrm{N}_{2}{ }^{1}$ and $\mathrm{CO}^{2}$ at a unique heterometallic [7Fe9S-Mo-C- $R$-homocitrate] active site, the iron-molybdenum cofactor (FeMoco, Figure 1a). ${ }^{3-4}$ In both cases, catalysis involves an electron loading phase prior to substrate binding, suggesting that coordination of both $\mathrm{N}_{2}$ and $\mathrm{CO}$ is sensitive to the redox level of the cofactor. While atomic level details remain elusive, binding of $\mathrm{N}_{2}$ does not occur until FeMoco has been reduced by at least three electrons relative to its resting state, ${ }^{5}$ whereas only one or two reducing equivalents are required to initiate $\mathrm{CO}$ binding. ${ }^{6-8}$ As both a substrate and reversible inhibitor of catalysis, $\mathrm{CO}$ is an excellent reporter of substrate interactions with FeMoco. While an $\mathrm{N}_{2}$-bound form of the cofactor has yet to be unambiguously characterized, both terminal and bridging $\mathrm{CO}$ adducts of FeMoco have been spectroscopically detected during turnover. $^{9-11}$ One of these intermediates has recently been crystallographically characterized, demonstrating that CO bridges between Fe2 and Fe6. ${ }^{12}$ Several spectroscopic and biochemical studies support a central role for these two belt iron sites in binding of $\mathrm{CO}$ in several proposed intermediates, ${ }^{7,11,13}$ as well as other substrates, ${ }^{14-16}$ including perhaps $\mathrm{N}_{2} \cdot{ }^{17}$

Despite progress in their spectroscopic and structural characterization, no information is currently available about the distribution of oxidation states in CO-bound forms of FeMoco. In addition to controlling substrate access to the cofactor, ${ }^{18}$ it has been suggested that the local protein environment can induce some degree of valence localization within the cluster. Notably, spatially resolved anomalous dispersion refinement of FeMoco in its resting state revealed that the specific iron centers which have been implicated as $\mathrm{CO}$ binding sites lie on a more oxidized edge of the cofactor. ${ }^{19}$ Depending on the location of hydride accumulation, which has been proposed to occur during the electron loading phase of catalysis, ${ }^{10}$ internal electron transfer events may be required for $\mathrm{CO}$ to bind at this oxidized edge.

Although clearly electron loading of FeMoco plays a key role in allowing the cofactor to bind $\pi$-acids, it is challenging to untangle the effects of pure redox chemistry from concomitant structural changes that may occur upon reduction. Moreover, the energetic consequences of internal redox rearrangements which may accommodate substrate binding have not been experimentally determined. Despite capturing essential structural features of the biological system, ${ }^{20-}$ ${ }^{22}$ synthetic high spin iron(II/III) clusters generally lack sitedifferentiation due to reliance on self-assembly strategies, complicating studies of ligand binding at discrete reactive site(s). Furthermore, large structural changes and redistribution of ligands often occur upon redox changes or CO binding in iron cluster models. ${ }^{23-26}$ While well-defined multimetallic systems which exhibit reactivity relevant to nitrogenase have been reported, ${ }^{21,27-38}$ to date there are no reported studies on the energetics of $\mathrm{CO}$ binding in multiple, isostructural redox states of a synthetic, high spin iron cluster. 
A.

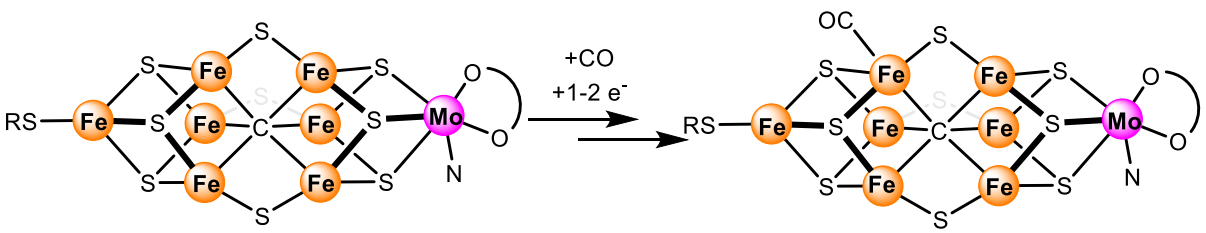

Resting State $\left(\mathrm{E}_{0}\right) \quad$ One proposed low $P_{\text {co }}$ intermediate

$\mathrm{Fe}_{3}{ }_{3} \mathrm{Fe}^{\mathrm{III}}{ }_{4} \mathrm{Mo}$ III $\quad$ High spin, high oxidation state

Electronically and sterically site-differentiated Mono- and dicarbonyl intermediates Reversible CO inhibition

Binding on the more oxidized cluster face

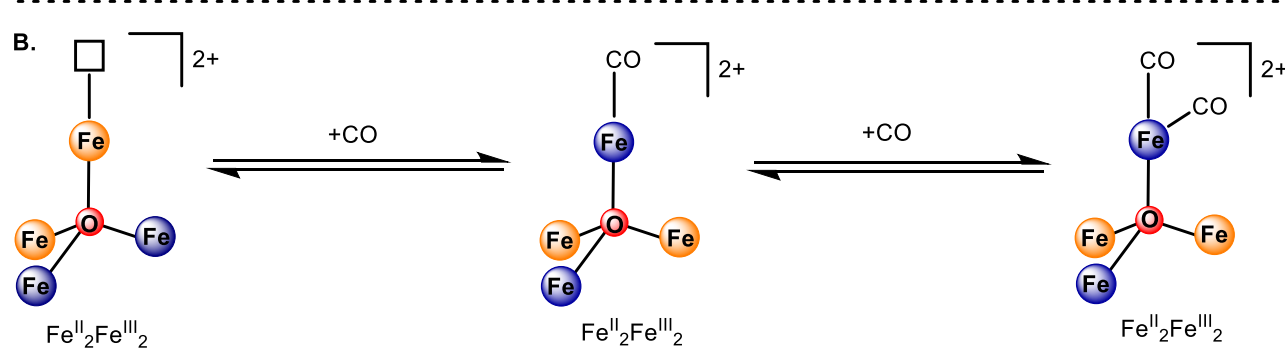

\footnotetext{
High spin, site-differentiated

Reversible binding in redox states $\mathrm{Fe}_{4}{ }_{4}$ through $\mathrm{Fe}^{\prime \prime} \mathrm{Fe}^{\prime \prime \prime}{ }_{3}$

Binding on the more oxidized cluster face

Evaluate energetic contributions of electron loading and (re)distribution
}

FIGURE 1. Iron-Molybdenum cofactor (FeMoco) of nitrogenase and synthetic model complexes. (A) Redox-dependent binding of CO by FeMoco. (B) Inorganic core of synthetic model clusters which reversibly bind $\mathrm{CO}$ in four isostructural redox states.

In order to evaluate the influence of redox chemistry on ligand binding and activation phenomena, our group has recently developed synthetic strategies to access site-differentiated tetranuclear clusters featuring a coordinatively unsaturated metal center. ${ }^{39-41}$ Here, we report the synthesis of a redox series of high spin, site-differentiated iron clusters which reversibly bind $\mathrm{CO}$ in four redox states $\left(\mathrm{Fe}^{\mathrm{II}} 4\right.$ through $\mathrm{Fe}^{\mathrm{II}} \mathrm{Fe}^{\mathrm{III}}{ }_{3}$ ). We observe that coordination of $\mathrm{CO}$ to both the $\mathrm{Fe}_{2}{ }_{2} \mathrm{Fe}^{\mathrm{III}} 2$ and $\mathrm{Fe}^{\mathrm{II}} \mathrm{Fe}^{\mathrm{III}}{ }_{3}$ redox state of the cluster involves an internal redox reorganization; binding of $\mathrm{CO}$ at the apical $\mathrm{Fe}^{\mathrm{III}}$ site induces an internal electron transfer from a distal $\mathrm{Fe}^{\mathrm{II}}$ center. Studying the energetics of $\mathrm{CO}$ binding, we observe only small enhancements (at most $\sim 400$-fold) in the affinity for $\mathrm{CO}$ due to pure redox chemistry in these high spin, valence localized iron clusters, in contrast to the large enhancements ( $>10^{5}$-fold) in $\pi$-acid affinity reported for monometallic and low spin bimetallic iron complexes, where redox chemistry occurs exclusively at the ligand binding site. Deconvoluting the effect of redox at specific sites within the cluster, we demonstrate that electron-loading at metal centers remote from the substrate binding site has a relatively small influence on the $\mathrm{CO}$ binding energetics. Additionally, a small energetic cost is associated with redistribution of electrons in response to ligand binding which explains why coordination of $\mathrm{CO}$ at an oxidized face of the cluster remains facile.

\section{RESULTS AND DISCUSSION}

A Redox Series of Site-Differentiated, Tetranuclear Iron Clusters. In order to evaluate the effect of electron loading and (re)distribution on CO binding in high spin iron clusters, we targeted the synthesis of imidazolate bridged congeners of our previously reported ${ }^{41}$ pyrazolate bridged iron clusters. The differences in the electronic properties of the ligands was probed by DFT calculations (B3LYP/6$31 \mathrm{G}+(\mathrm{d}, \mathrm{p}))$ for 3-methylpyrazolate and 1-methylimidazolate as simplified models. The frontier orbitals of 3methylpyrazolate include two N-based donor molecular orbitals (MOs) of $\sigma$-symmetry (HOMO-3 and HOMO-4) with respect to interactions with individual ligands. Nearly equal contributions from atomic orbitals localized on either nitrogen atom (Figure 2A) are observed. This is in contrast to 1methylimidazolate where the analogous $\sigma$-donor orbitals are spatially distinct, with the HOMO largely localized on $\mathrm{C}$ (Figure 2B). Moreover, the energy separation between the two $\sigma$-donor orbitals (relative to the HOMO) is larger for 1methylimidazolate and, due to the lower electronegativity of $\mathrm{C}$, these orbitals lie at higher energy than those of 3methylpyrazolate. By tuning the steric bulk of the imidazolate to orient the ligand with its $\mathrm{C}$-donors binding the apical metal, this electronic desymmetrization of the bridging ligand was anticipated to enhance electron density of the apical metal (relative to the distal triiron core). This electronic effect increases the propensity to oxidation with imidazolate compared to pyrazolate ligands at the apical metal site. 


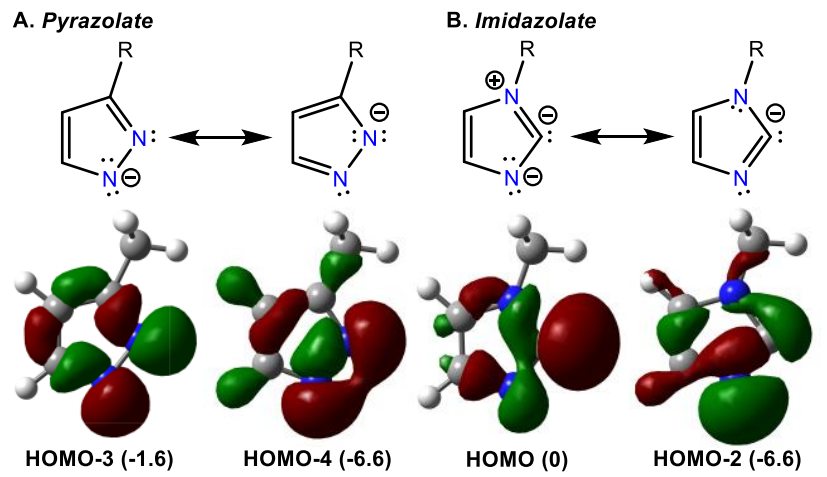

FIGURE 2. (A) Calculated $\sigma$-donor MO's for 3-methylpyrazolate (B) Calculated $\sigma$-donor MO's for 1-methylimidazolate. Orbital energies (relative to the HOMO, respectively) are given in parentheses, and isosurfaces are shown at the $0.04 \mathrm{e} \AA^{-3}$ level. For both pyrazolate and imidazolate anions, there is an additional, higher energy resonance structure (not depicted).

The desired clusters are accessible in three steps (Scheme 1) from the triiron precursor $\mathrm{LFe}_{3}(\mathrm{OAc})_{3 .} .^{42}$ Complete acetate removal was effected by treatment of $\mathrm{LFe}_{3}(\mathrm{OAc})_{3}$ with an excess of $\mathrm{Me}_{3} \mathrm{SiOTf}$ in dichloromethane, affording the precursor $\mathrm{LFe}_{3}(\mathrm{OTf})_{3}(\mathbf{1})$ with more labile triflate ligands (Supplementary Fig. 86). Addition of 1-phenyl imidazole (PhIm-H, 3.3 equiv.) and iodosobenzene (PhIO) to a suspension of $\mathbf{1}$ in tetrahydrofuran affords the PhIm-H coordinated species $\left[\mathrm{LFe}_{3} \mathrm{O}(\mathrm{PhIm}-\mathrm{H})_{3}\right][\mathrm{OTf}]_{3}$ (2, Supplementary Fig. 87). Deprotonation of $\mathbf{2}$ with sodium hexamethyldisilazide ( $\mathrm{Na}\left[\mathrm{N}\left(\mathrm{SiMe}_{3}\right)_{2}\right], 3.2$ equiv.) followed by addition of $\mathrm{FeCl}_{2}$ affords the desired species $\left[\mathrm{LFe}_{3} \mathrm{O}(\mathrm{PhIm})_{3} \mathrm{Fe}\right][\mathrm{OTf}]_{2}(3)$. A single crystal X-ray diffraction study confirms the formation of a tetranuclear iron cluster (Figure 3a), where the bond metrics within the $\mathrm{Fe}_{4}\left(\mu_{4}-\mathrm{O}\right)$ motif are diagnostic of metal oxidation states. ${ }^{39-41}$ For the structurally homologous pyrazolate bridged clusters $\left[\mathrm{LFe}_{3} \mathrm{O}(\mathrm{PhPz})_{3} \mathrm{Fe}\right][\mathrm{OTf}]_{\mathrm{n}}(\mathrm{n}=1-3)$, the distances between the distal, six-coordinate iron centers ( $\mathrm{Fe} 1, \mathrm{Fe} 2, \mathrm{Fe} 3$, respectively) and the interstitial oxygen atom (01) elongate upon reduction (average Fe1/2/3-01 distances: $1.96 \AA$ for $\mathrm{Fe}^{\mathrm{III}}$ and $2.07 \AA$ A for $\left.\mathrm{Fe}^{\mathrm{II}}\right) .{ }^{41}$ The observation of two long (2.1480(19) and 2.093(2) $\AA$ ) and one short $(1.983(2) \AA ̊)$ bond distance between the interstitial oxygen (01) and the iron centers $\mathrm{Fe} 1, \mathrm{Fe} 2$, and $\mathrm{Fe} 3$ suggests a valence localized $\left[\mathrm{Fe}^{\mathrm{II}}{ }_{2} \mathrm{Fe}^{\mathrm{III}}\right]$ assignment for the basal triiron core of 3. This indicates an $\mathrm{Fe}^{\mathrm{III}}$ assignment for the apical Fe4 center, consistent with its short Fe4-01 distance (1.8128(19) A, Supplementary Table 4).

For comparison, the isoelectronic pyrazolate bridged cluster $\left[\mathrm{LFe}_{3} \mathrm{O}(\mathrm{PhPz})_{3} \mathrm{Fe}\right][\mathrm{OTf}]_{2}$ features a significantly longer Fe4-01 distance (1.972(2) $\AA$ ), consistent with its assignment as $\mathrm{Fe}^{\mathrm{II}}$ based on ${ }^{57} \mathrm{Fe}$ Mössbauer spectroscopy. ${ }^{41}$ This indicates that, unlike $\mathbf{3}$, both of the ferric centers in $\left[\mathrm{LFe}_{3} \mathrm{O}(\mathrm{PhPz})_{3} \mathrm{Fe}\right][\mathrm{OTf}] 2$ are localized within the basal

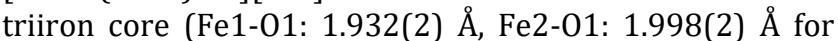
$\left.\left[\mathrm{LFe}_{3} \mathrm{O}(\mathrm{PhPz})_{3} \mathrm{Fe}\right][\mathrm{OTf}] 2\right)^{41}$ Consistent with our computational studies, these results demonstrate that substitution of the 3-phenyl pyrazolate ligands by 1-phenyl imidazolate indeed makes the apical binding site more electron rich, facilitating oxidation at $\mathrm{Fe} 4$. For the pyrazolate bridged clus- ters $\left[\mathrm{LFe}_{3} \mathrm{O}(\mathrm{PhPz})_{3} \mathrm{Fe}\right][\mathrm{OTf}]_{\mathrm{n}}(\mathrm{n}=1-3)$, oxidation of the apical Fe4 center was not observed in the absence of an additional anionic donor. ${ }^{41}$

\section{SCHEME 1. Synthesis of tetranuclear iron clusters ${ }^{43}$}

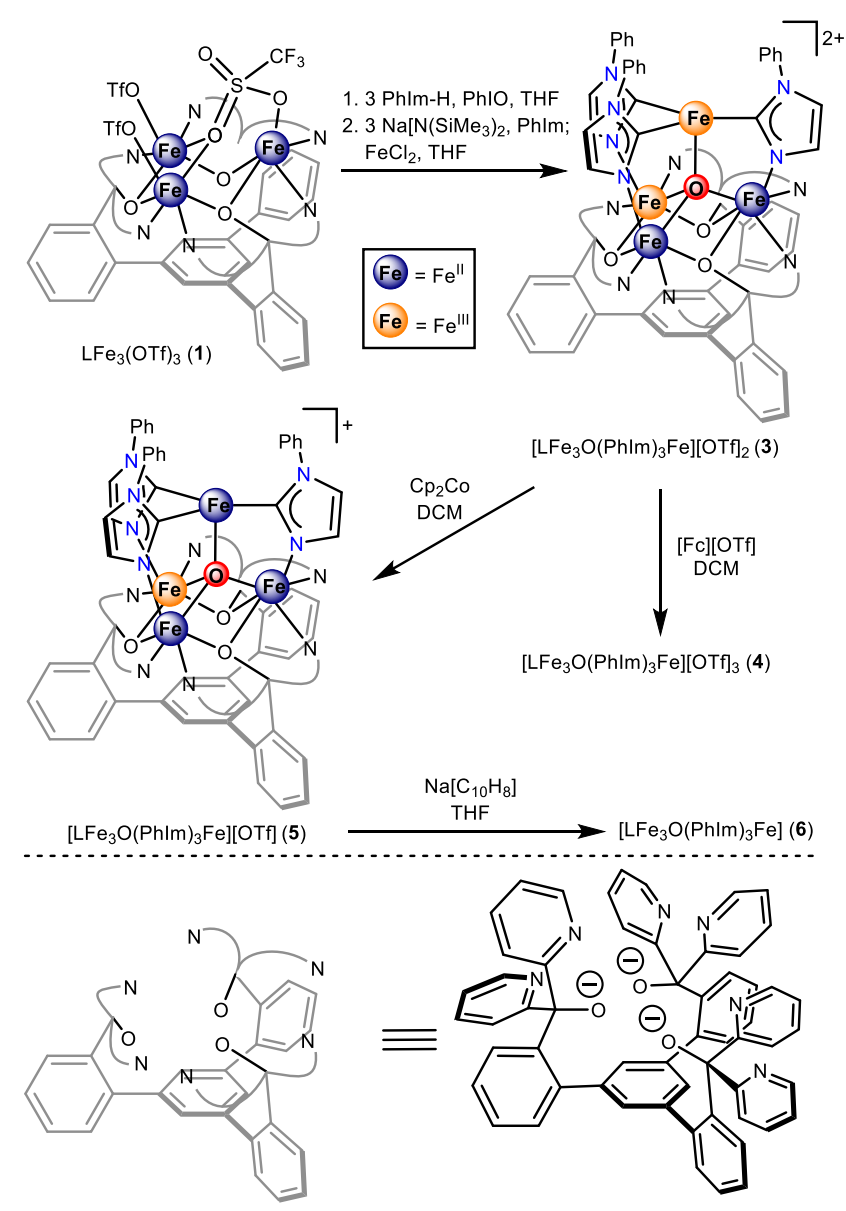

In order to interrogate the effect of the imidazolate ligands on the electronic properties of the cluster as a whole, the $\mathrm{CV}$ of $\mathbf{3}$ was recorded in dichloromethane (Figure 4). Three (quasi)-reversible one electron redox events are observed at $-1.013 \mathrm{~V},-0.200 \mathrm{~V}$, and $+0.450 \mathrm{~V}$ (Supplementary Table 1, all vs. $\mathrm{Fc} / \mathrm{Fc}^{+}$). The first two electrochemical events are assigned to the $\mathrm{Fe}^{\mathrm{II}}{ }_{3} \mathrm{Fe}^{\mathrm{III}} / \mathrm{Fe}^{\mathrm{II}}{ }_{2} \mathrm{Fe}^{\mathrm{III}}{ }_{2}(-1.013 \mathrm{~V})$ and $\mathrm{Fe}_{2}{ }_{2} \mathrm{Fe}^{\mathrm{III}}{ }_{2} / \mathrm{Fe}^{\mathrm{II}} \mathrm{Fe}^{\mathrm{III}}{ }_{3}(-0.200 \mathrm{~V})$ redox couples. These potentials are cathodically shifted by $286 \mathrm{mV}$ and $182 \mathrm{mV}$, respectively, relative to the analogous redox events for the pyrazolate bridged homolog $\left[\mathrm{LFe}_{3} \mathrm{O}(\mathrm{PhPz})_{3} \mathrm{Fe}\right][\mathrm{OTf}]_{2}$ (Supplementary Table 1), ${ }^{41}$ demonstrating the enhanced donor properties of 1-phenyl imidazolate relative to 3-phenyl pyrazolate (Figure 5). The final quasi-reversible electrochemical event at $+0.450 \mathrm{~V}$ is assigned to the $\mathrm{Fe}^{\mathrm{II}} \mathrm{Fe}^{\mathrm{III}}{ }_{3} / \mathrm{Fe}^{\mathrm{III}} 4$ couple. Notably, the corresponding oxidation was not observed in the $\mathrm{CV}$ of $\left[\mathrm{LFe}_{3} \mathrm{O}(\mathrm{PhPz})_{3} \mathrm{Fe}\right][\mathrm{OTf}]_{2}$ at potentials up to $1 \mathrm{~V}$. However, the CV of $\left[\mathrm{LFe}_{3} \mathrm{O}(\mathrm{PhPz})_{3} \mathrm{Fe}\right][\mathrm{OTf}]_{2}$ in dichloromethane exhibits an additional reduction at $-1.733 \mathrm{~V}$ assigned to the $\mathrm{Fe}^{\mathrm{II}_{4}} / \mathrm{Fe}^{\mathrm{II}} 3 \mathrm{Fe}^{\mathrm{III}}$ redox event. ${ }^{41}$ At similar potentials, the CV of $\mathbf{3}$ exhibits a large reductive wave (Supplementary Fig. 46), suggesting that the all-ferrous cluster reacts with dichloromethane. Notwithstanding, the $\mathrm{Fe}^{\mathrm{II}}{ }_{4} / \mathrm{Fe}^{\mathrm{II}}{ }_{3} \mathrm{Fe}^{\mathrm{III}}$ redox event becomes (quasi)-reversible (- 
$1.868 \mathrm{~V}$ ) when the $\mathrm{CV}$ of $\mathbf{3}$ is recorded in tetrahydrofuran (Supplementary Fig 49).
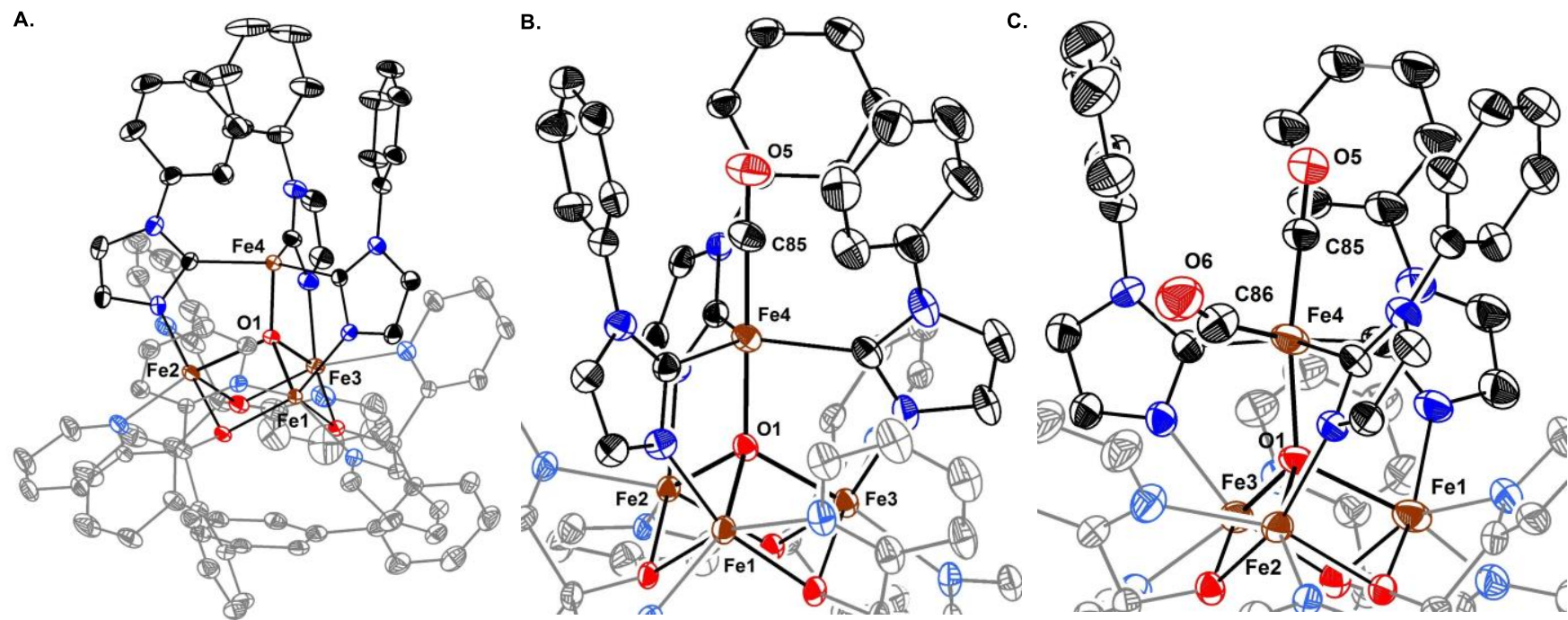

FIGURE 3. Solid state structures of 3, 5-CO and 3-(CO) 2 . Hydrogen atoms and outer sphere counterions not shown for clarity. (A) $\left.\left[\mathrm{LFe}{ }_{3} \mathrm{O}(\mathrm{PhIm})_{3} \mathrm{Fe}\right]_{[0 \mathrm{OTf}}\right]_{2}$ (3). (B) [LFe $\left.3 \mathrm{O}(\mathrm{PhIm})_{3} \mathrm{Fe}(\mathrm{CO})\right][\mathrm{OTf}]$ (5-CO) (C) [LFe $\left.3(\mathrm{OhIm})_{3} \mathrm{Fe}(\mathrm{CO})_{2}\right][\mathrm{OTf}]_{2}$ (3-(CO) $)_{2}$.

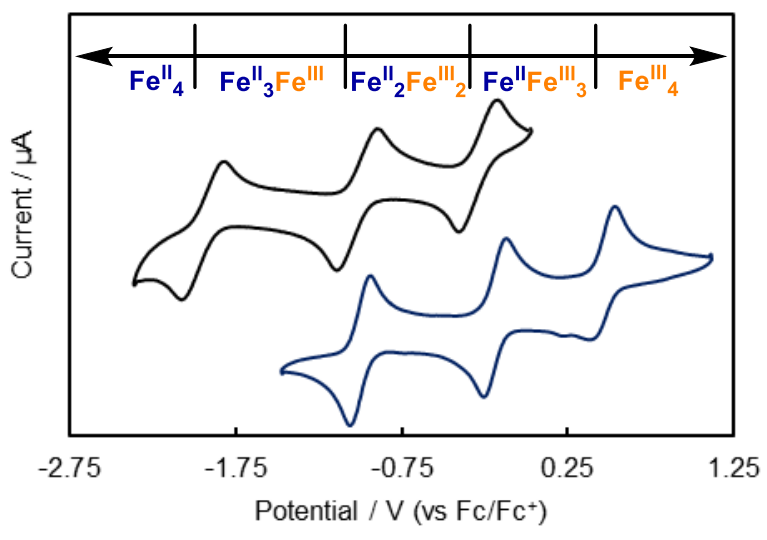

FIGURE 4. Cyclic voltammetry of $\mathbf{3}$ in THF (top, black) and $\mathrm{CH}_{2} \mathrm{Cl}_{2}$ (bottom, blue) with $0.1 \mathrm{M}\left[n \mathrm{Bu}_{4} \mathrm{~N}\right]\left[\mathrm{PF}_{6}\right]$ at a scan rate of $100 \mathrm{mV} / \mathrm{s}$. For the $\mathrm{Fe}^{\mathrm{II}} \mathrm{Fe}^{\mathrm{III}} 3 / \mathrm{Fe}^{\mathrm{III}} 4$ couple, two reductive features are observed and they become better resolved with faster scan rates. This may arise from reversible triflate binding, interconverting $\quad\left[\mathrm{LFe}{ }_{3} \mathrm{O}(\mathrm{PhIm})_{3} \mathrm{Fe}\right][\mathrm{OTf}]_{4}$ and $\left[\mathrm{LFe}{ }_{3} \mathrm{O}(\mathrm{PhIm})_{3} \mathrm{Fe}\right.$ (OTf)][OTf $]_{3}$.

Consistent with its electrochemical behavior, treatment of 3 with [Fc][0Tf] in dichloromethane affords a new paramagnetic species which, following crystallization, was structurally characterized as $\left[\mathrm{LFe}_{3} \mathrm{O}(\mathrm{PhIm})_{3} \mathrm{Fe}\right][\mathrm{OTf}]_{3}(4)$. Addition of $\mathrm{Cp}_{2} \mathrm{Co}$ to a solution of $\mathbf{3}$ in dichloromethane cleanly affords the reduced species $\left[\mathrm{LFe}_{3} \mathrm{O}(\mathrm{PhIm})_{3} \mathrm{Fe}\right][\mathrm{OTf}]$ (5). Further reduction of $\mathbf{5}$ with sodium napthalenide $\left(\mathrm{Na}\left[\mathrm{C}_{10} \mathrm{H}_{8}\right]\right)$ in tetrahydrofuran affords an insoluble blue powder, assigned as the all-ferrous cluster, $\left[\mathrm{LFe}_{3} \mathrm{O}(\mathrm{PhIm})_{3} \mathrm{Fe}\right](6)$, on the basis of Mössbauer spectroscopy (Supplementary Fig. 75)..$^{44}$

The solid-state structures of $\mathbf{4}$ and $\mathbf{5}$ demonstrate that the basic geometric features of $\mathbf{3}$ are maintained throughout the redox series (Supplementary Fig. 90 and 91), where the bond metrics within the $\mathrm{Fe}_{4}\left(\mu_{4}-0\right)$ motif reveal the primary locus of redox chemistry (Supplementary Table 4). Oxidation of $\mathbf{3}$ to $\mathbf{4}$ results in a significant contraction of the Fe301 distance from 2.092(2) A to 1.983(4)Å, consistent with oxidation within the basal triiron core. Conversely, reduction of 3 to 5 results in an elongation of the Fe4-01 distance from $1.8128(19) \AA$ to $1.883(4) \AA$, suggesting reduction of the apical iron from $\mathrm{Fe}^{\mathrm{III}}$ to $\mathrm{Fe}^{\mathrm{II}}$. The insolubility of 6 precludes structural characterization.

The crystallographic assignment of redox distributions in 3-6 are further corroborated by their zero field ${ }^{57} \mathrm{Fe}$ Mössbauer spectra. The $80 \mathrm{~K}$ Mössbauer spectrum of 3 (Supplementary Fig. 64) was best fit with four quadrupole doublets, corresponding to four inequivalent iron centers. Two quadrupole doublets with isomer shifts of $1.03 \mathrm{~mm} / \mathrm{s}$ and 1.14 $\mathrm{mm} / \mathrm{s}\left(\left|\Delta \mathrm{E}_{\mathrm{Q}}\right|\right.$ of $3.13 \mathrm{~mm} / \mathrm{s}$ and $3.22 \mathrm{~mm} / \mathrm{s}$, respectively) are characteristic of six-coordinate, high spin ferrous centers, while the quadrupole doublet with an isomer shift of 0.39 $\mathrm{mm} / \mathrm{s}\left(\left|\Delta \mathrm{E}_{\mathrm{Q}}\right|=0.37 \mathrm{~mm} / \mathrm{s}\right)$ is consistent with the presence of one octahedral ferric ion. ${ }^{39-41}$ This results in an assignment of the core oxidation level as $\left[\mathrm{Fe}^{\mathrm{II}}{ }_{2} \mathrm{Fe}^{\mathrm{III}}\right]$, which is identical to that inferred from the solid state structure. The remaining quadrupole doublet, with an isomer shift of 0.19 $\mathrm{mm} / \mathrm{s}\left(\left|\Delta \mathrm{E}_{\mathrm{Q}}\right|=1.11 \mathrm{~mm} / \mathrm{s}\right)$, is attributed to the apical iron. Similar parameters have been observed for four coordinate, high spin ferric centers. ${ }^{20}$

Compared to the spectrum of 3 , the relative intensity of the diagnostic basal core $\mathrm{Fe}^{\mathrm{II}}$ resonance near $3 \mathrm{~mm} / \mathrm{s}$ decreases in $\mathbf{4}$, consistent with oxidation within the triiron core. The spectrum of $\mathbf{4}$ was best fit with four quadrupole doublets with parameters indicating the presence of only one six-coordinate, high spin ferrous center, maintenance of the apical, high spin $\mathrm{Fe}^{\mathrm{III}}$, and two high spin, six-coordinate ferric centers (Supplementary Fig. 72). Conversely, upon reduction of $\mathbf{3}$ to $\mathbf{5}$, there is no change in the relative intensity of the Lorentzian feature near $3 \mathrm{~mm} / \mathrm{s}$ (Supplementary Fig. 
74). Instead, a substantial change in the isomer shift of the quadrupole doublet assigned to the apical iron is observed $(\delta=0.19 \mathrm{~mm} / \mathrm{s}$ in 3 vs. $\delta=0.89 \mathrm{~mm} / \mathrm{s}$ in 5), suggesting one electron reduction at $\mathrm{Fe} 4$.

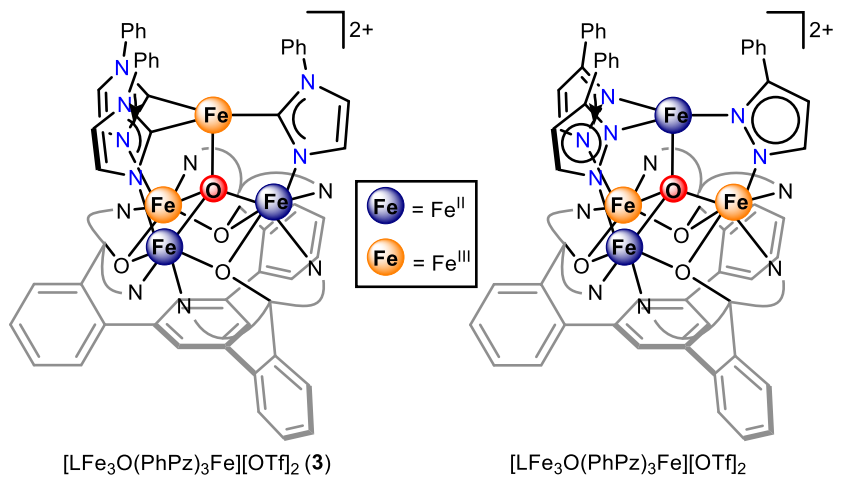

\section{Redox Properties}

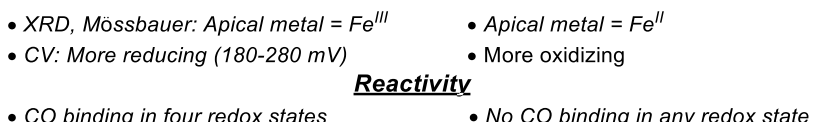

FIGURE 5. Comparison of the redox properties and reactivity of $\left[\mathrm{LFe}_{3} \mathrm{O}(\mathrm{PhIm})_{3} \mathrm{Fe}\right][\mathrm{OTf}]_{2}(3, \mathrm{left})$ and $\left[\mathrm{LFe}_{3} \mathrm{O}(\mathrm{PhPz})_{3} \mathrm{Fe}\right][\mathrm{OTf}]_{2}$ (right).

Electronic Structure of 3. In order to confirm the high spin assignment of the apical, four-coordinate Fe ${ }^{\text {III }}$ centers of $\mathbf{3}$ and 4 inferred by Mössbauer spectroscopy, additional spectroscopic studies were undertaken, with a focus on $\mathbf{3}$ which features the shortest Fe4-01 bond length. To assess the nature of the exchange coupling and the spin ground state, variable temperature (VT) magnetic susceptibility and variable temperature-variable field (VTVH) magnetization data were collected. The VT magnetic susceptibility data for 3 obtained between $1.8 \mathrm{~K}$ and $300 \mathrm{~K}$ at $0.1 \mathrm{~T}$ (Figure $6 \mathrm{a}$ ) indicate overall ferromagnetic coupling and an $S=4$ spin ground state. A plateau in the susceptibility is observed between $10-20 \mathrm{~K}$ at a value of $\sim 9.1 \mathrm{~cm}^{3} \mathrm{~K} \mathrm{~mol}^{-1}$ which decreases gradually to $6.4 \mathrm{~cm}^{3} \mathrm{~K} \mathrm{~mol}^{-1}$ at $300 \mathrm{~K}$. Below $10 \mathrm{~K}$, a drop in $\chi_{M} \mathrm{~T}$ is also observed, likely a result of zero-field splitting. The susceptibility data for 3 was fit between 1.8 and $300 \mathrm{~K}$ according to the spin Hamiltonian $H=\Sigma\left\{D\left(S_{z, i^{2}}{ }^{-}\right.\right.$ $\left.1 / 3\left(S_{i}\left(S_{i}+1\right)+g \mu_{B} S_{i} \cdot H\right)\right\}-2 J_{i j}\left(S_{i} \cdot S_{j}\right)$. A satisfactory simulation of the experimental data is obtained assuming all metal centers are locally high spin with isotropic exchange constants: $J_{14}=-29.2 \mathrm{~cm}^{-1}, J_{24}=-63.9 \mathrm{~cm}^{-1}, J_{34}=-28.8 \mathrm{~cm}^{-1}, J_{12}=J_{23}=-8.2$ $\mathrm{cm}^{-1}$ and $J_{13}=-9.5 \mathrm{~cm}^{-1}$ (for additional details see Supplementary Fig. 61). From these simulated parameters, the observed ferromagnetic behavior may be rationalized. Strong antiferromagnetic interactions of the apical $\mathrm{Fe}^{\mathrm{III}}$ (Fe4) with each of the metal centers of the triiron core $\left(\left|J_{\text {apical-core }}\right| \geq\right.$ $\left.3\left|J_{\text {core-core }}\right|\right)$ results in ferromagnetic alignment of the spins on $\mathrm{Fe} 1 / \mathrm{Fe} 2 / \mathrm{Fe} 3$ at low temperatures, affording an $S=4$ ground state.

Consistent with this spin coupling scheme, VTVH magnetization data collected between 1.8 and $9 \mathrm{~K}$ at fields of 1 to 7 $\mathrm{T}$ (Figure 6b) were well simulated with the system spin Hamiltonian $H=D S_{z}{ }^{2}+E\left(S_{x}^{2}+S_{y}{ }^{2}\right)+g \mu_{B} \boldsymbol{S} \cdot \mathbf{H}$. Due to the presence of zero field splitting, the VTVH magnetization data for 3 saturates near $5.4 \mu_{\mathrm{B}}$ at $1.8 \mathrm{~K}$ and $7 \mathrm{~T}$, below the expected
$\mathrm{M}=g S$ limit for $g=2.0$. However, the experimental data is well reproduced assuming an $S=4$ ground state with $g=$ 2.00, $D=-3.65 \mathrm{~cm}^{-1}$, and $\mid E / D /=0.33$. Consistent with its assignment as a non-Kramer's system with $D<0,{ }^{45}$ the Mössbauer spectrum of $\mathbf{3}$ at $2.3 \mathrm{~K}$ exhibits pronounced magnetic hyperfine splitting with well-resolved features between -7 and $8 \mathrm{~mm} / \mathrm{s}$ in an applied field of only $50 \mathrm{mT}$ (Supplementary Fig. 66). The parallel mode EPR spectrum of $\mathbf{3}$ in a propionitrile/butryonitrile (4:5) glass exhibits a sharp feature with $g \sim 17.2$ at $4.5 \mathrm{~K}$ which is assigned to a transition within the $M_{s}=+/-4$ doublet (Supplementary Fig. 63).
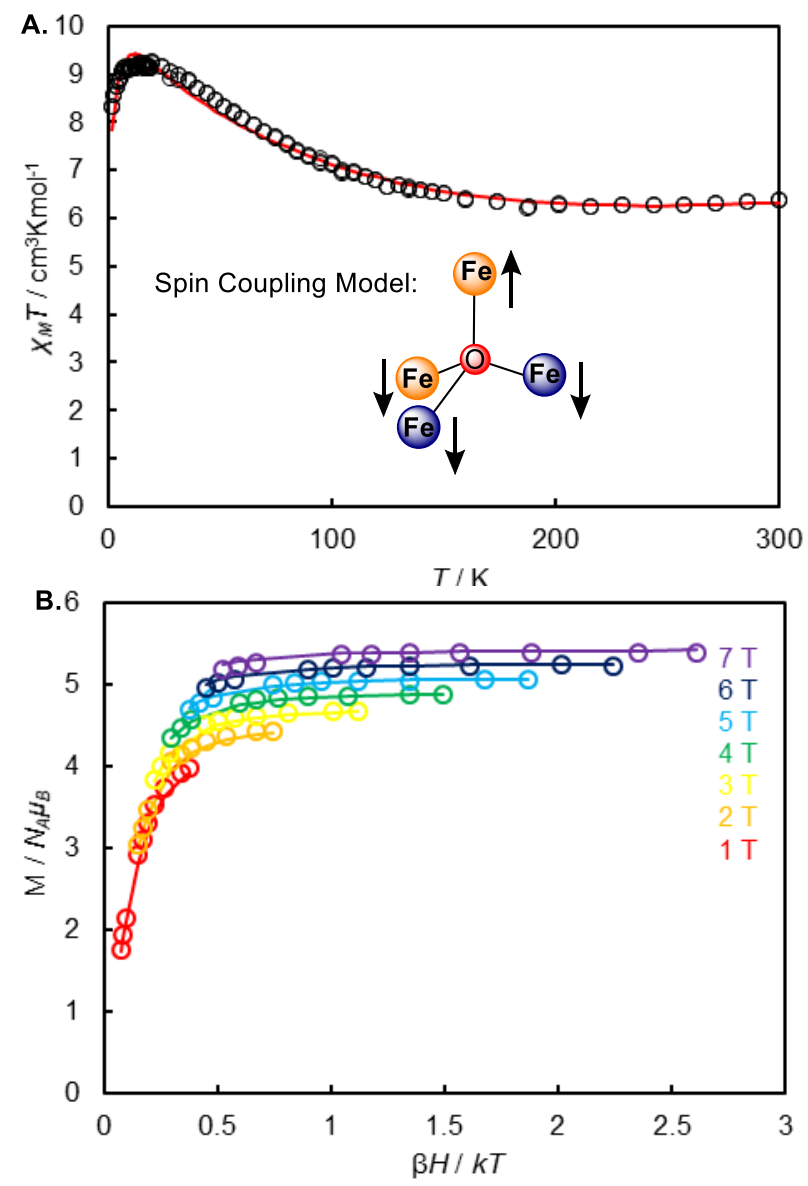

FIGURE 6. (A) Variable temperature direct current magnetic susceptibility data for $\left[\mathrm{LFe}_{3} \mathrm{O}(\mathrm{PhIm})_{3} \mathrm{Fe}\right][\mathrm{OTf}]_{2}$ (3) obtained between $1.8 \mathrm{~K}$ and $300 \mathrm{~K}$ at $0.1 \mathrm{~T}$. Simulated according to the spin Hamiltonian $H=\Sigma\left\{D\left(S_{z, i} 2-1 / 3\left(S_{i}\left(S_{i}+1\right)+g \mu_{B} S_{i} \cdot H\right)\right\}-2 J_{i j}\left(S_{i} \cdot S_{j}\right)\right.$ with all metal centers locally high spin. For full simulation parameters, see the Supporting Information. (B) Variable temperature-variable field magnetization data for $\left[\mathrm{LFe}{ }_{3} \mathrm{O}(\mathrm{PhIm})_{3} \mathrm{Fe}\right][\mathrm{OTf}]_{2}(3)$ between 1.8 and $9 \mathrm{~K}$ at fields of 1 to $7 \mathrm{~T}$. Simulated according to the system spin Hamiltonian $H=$ $D S_{z}^{2}+E\left(S_{x}^{2}+S_{y}^{2}\right)+g \mu_{B} \mathbf{S} \cdot \mathbf{H}$ with $g=2.00, D=-3.65 \mathrm{~cm}^{-1}$, and $|E / D|=0.33$.

Co Binding Equilibria of 3. Having confirmed the high spin assignment of the apical $\mathrm{Fe}^{\mathrm{III}}$ center in $\mathbf{3}$, we explored its reactivity with $\mathrm{CO}$ (Figure 7). In this regard, variable temperature IR spectroscopy indicated the formation of both mono- (3-CO) and dicarbonyl (3-(CO) 2 ) adducts of $\mathbf{3}$ (Supplementary Fig. 18). The IR spectrum of $\mathbf{3}$ measured at 195 $\mathrm{K}$ in CO-saturated dichloromethane following an Ar purge 
exhibited an intense feature at $1944 \mathrm{~cm}^{-1}$ (3-CO) in addition to weaker features at $2014 \mathrm{~cm}^{-1}$ and $1960 \mathrm{~cm}^{-1}$ (3-(CO) 2 ). Warming the solution to $273 \mathrm{~K}$ with stirring under Ar results in loss of the features at 2014 and $1960 \mathrm{~cm}^{-1}$ and a decrease of intensity at $1944 \mathrm{~cm}^{-1}$. Upon further warming to room temperature, no $\mathrm{CO}$ vibrational features were observed.

The temperature dependent formation of both 3-CO and 3-(CO) 2 was confirmed by ${ }^{1} \mathrm{H}-\mathrm{NMR}$ studies. Cooling solutions of $\mathbf{3}$ in either dichloromethane- $d_{2}$ (Supplementary Fig. 27 ) or acetone- $d_{6}$ (Supplementary Fig. 37) under an atmosphere of CO from room temperature initially affords 3-CO

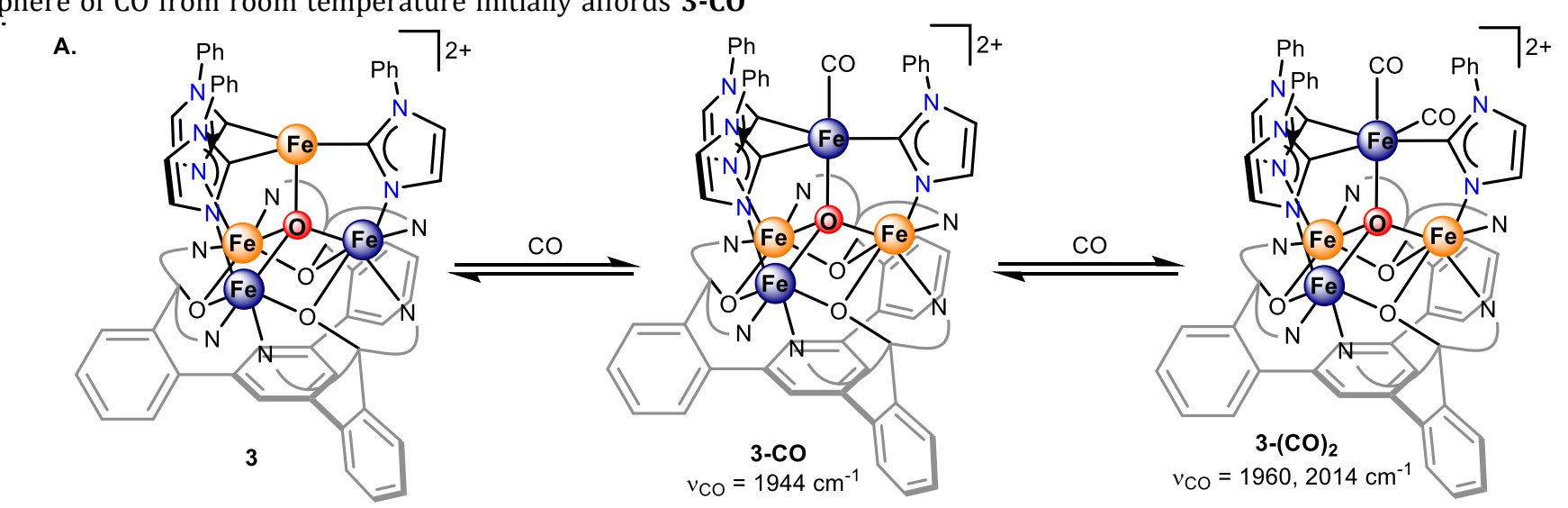

B.

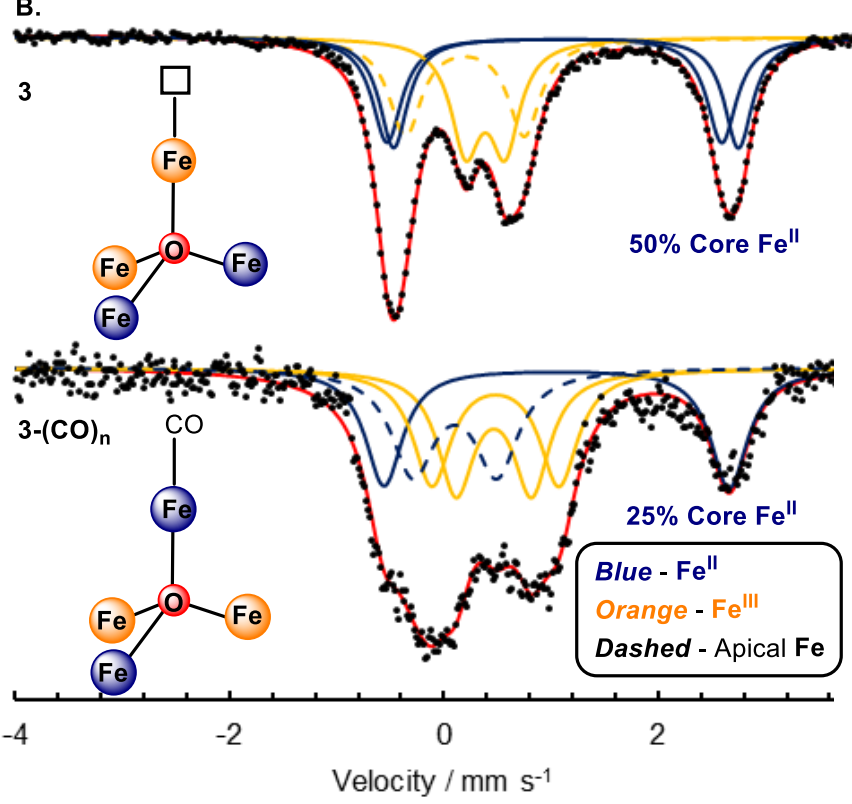

C. as the major species, though an additional species simultaneously grows in. Further cooling results in the loss of 3-CO and complete conversion to this more asymmetric species, assigned as 3-(CO)2. Confirmation of this assignment was obtained by crystallization from solutions of $\mathbf{3}$ at low temperature under an atmosphere of $\mathrm{CO}$, which afforded crystals of 3-(CO)2 suitable for XRD. The solid state structure of 3-(CO) 2 confirms that both CO ligands bind Fe4 (Figure 3c). Warming solutions of $\mathbf{3 - ( C O ) _ { 2 }}$ from $198 \mathrm{~K}$ back to room temperature confirms that these temperature dependent CO binding events are fully reversible.

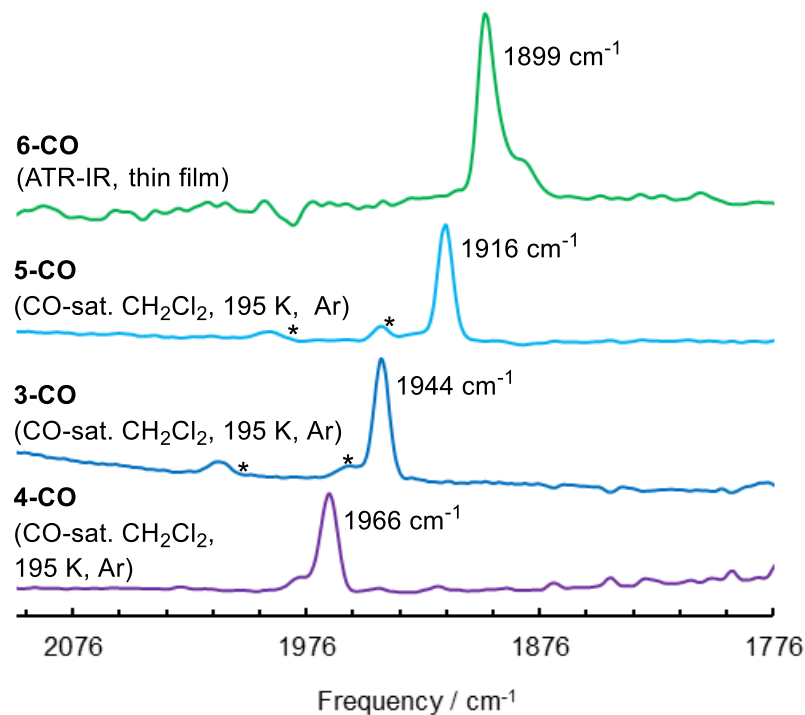

FIGURE 7. Binding of $\mathrm{CO}$ by $\left[\mathrm{LFe}_{3} \mathrm{O}(\mathrm{PhIm})_{3} \mathrm{Fe}\right][\mathrm{OTf}]_{2}$ (3) induces an internal electron transfer. (A) Cooling solutions of $\left[\mathrm{LFe}_{3} \mathrm{O}(\mathrm{PhIm})_{3} \mathrm{Fe}\right][\mathrm{OTf}]_{2}$ (3) under $\mathrm{CO}$ initially affords the monocarbonyl [LFe $\left.{ }_{3} \mathrm{O}(\mathrm{PhIm})_{3} \mathrm{Fe}(\mathrm{CO})\right][\mathrm{OTf}]_{2}$ (3-CO). Further cooling converts 3-CO into the dicarbonyl [ $\left.\left.\mathrm{LFe}_{3} \mathrm{O}(\mathrm{PhIm})_{3} \mathrm{Fe}(\mathrm{CO})_{2}\right]_{[0 \mathrm{Tf}}\right]_{2}$ (3-(CO) $\left.)_{2}\right)$ (B) Top: Zero field ${ }^{57} \mathrm{Fe}$ Mössbauer spectrum (80 K, microcrystalline material) of $\left[\mathrm{LFe}_{3} \mathrm{O}(\mathrm{PhIm})_{3} \mathrm{Fe}\right](\mathrm{OTf})_{2}$ confirms the presence of two core $\mathrm{Fe}$ II centers (50\% total iron). (Bottom): Mössbauer spectrum of $\left[\mathrm{LFe}_{3} \mathrm{O}(\mathrm{PhIm})_{3} \mathrm{Fe}(\mathrm{CO})_{n}\right][\mathrm{OTf}]_{2}\left(3-(\mathbf{C O})_{n}\right)$ in $\mathrm{CO}$-saturated 2,6-lutidine $\left(f . p .=-5^{\circ} \mathrm{C}\right)$ demonstrates that binding of $\mathrm{CO}$ results in a change of the core redox level from [ $\left.\mathrm{Fe}_{2}{ }_{2} \mathrm{Fe}^{\mathrm{III}}\right]$ to $\left[\mathrm{Fe}^{\mathrm{II}} \mathrm{Fe}^{\mathrm{III}} 2\right]$, with electron transfer to the site of $\mathrm{CO}$ binding. See the Supporting Information for full simulation details. (C) IR spectroscopy illustrates the influence of redox chemistry on $v_{\text {co }}$ for the monocarbonyl complexes described herein. The observed shifts in $v_{\text {co }}$ of only 20-30 $\mathrm{cm}^{-1}\left(\mathbf{6}-\mathbf{C O}: 1899 \mathbf{c m}^{-1}, \mathbf{5}-\mathbf{C O}: 1916 \mathrm{~cm}^{-1}, \mathbf{3 - C O}\right.$ : $1944 \mathrm{~cm}^{-1}$, 4-CO: $1966 \mathrm{~cm}^{-1}$ ) support an Fe $\mathrm{FI}_{-\mathrm{CO}}$ assignment across the series, implying that redox reorganization accompanies CO binding in $\mathbf{3}$ and $\mathbf{4}$. An asterisk denotes features associated with the dicarbonyl complexes. 
In the absence of redox reorganization, binding of $\mathrm{CO}$ by 3 would afford an apical Fe ${ }^{I I I}-\mathrm{CO}$ unit in 3-CO (Table 1). However, with few exceptions, ${ }^{46-49} \mathrm{Fe}^{\mathrm{III}}$ centers generally display no affinity for C0.50 Alternatively, we envisioned that an internal electron transfer ( $i$-ET) from a distal Fe ${ }^{\mathrm{II}}$ site might accommodate coordination of CO (Figure 7a). Based on the diagnostic features associated with the basal core $\mathrm{Fe}^{\mathrm{II}}$ centers in these clusters, ${ }^{39-41}$ Mössbauer spectroscopy serves as a convenient tool to determine whether redox reorganization accompanies CO binding. ${ }^{51}$ The zero field Mössbauer spectrum $(80 \mathrm{~K})$ obtained by freezing a $\mathrm{CO}$ saturated solution of 3 in 2,6-lutidine (f.p. $=-5^{\circ} \mathrm{C}$ ) reveals a significant loss of basal $\mathrm{Fe}^{\mathrm{II}}$ intensity (Supplementary Fig. 77). The spectrum can be satisfactorily fit to a mixture of 3 (CO)n (61\%) and 3 (39\%) (Supplementary Fig. 78). The Mössbauer spectrum of 3-(CO)n (Figure 7b, bottom) obtained following subtraction of residual 3 reveals a single quadrupole doublet ( $25 \%$ total iron) with an isomer shift near $1 \mathrm{~mm} / \mathrm{s}\left(\delta=1.05 \mathrm{~mm} / \mathrm{s},\left|\Delta \mathrm{E}_{\mathrm{Q}}\right|=3.22 \mathrm{~mm} / \mathrm{s}\right)$, indicating the presence of a single core ferrous center and a change in the core redox level from $\left[\mathrm{Fe}^{\mathrm{II}}{ }_{2} \mathrm{Fe}^{\mathrm{III}}\right]$ to $\left[\mathrm{Fe}^{\mathrm{II}} \mathrm{Fe}^{\mathrm{III}}{ }_{2}\right]$ following binding of $\mathrm{CO}$. The simulated Mössbauer parameters associated with the apical iron center of $3-(\mathbf{C O})_{\mathbf{n}}(\delta=0.10 \mathrm{~mm} / \mathrm{s}$, $\left|\Delta \mathrm{E}_{\mathrm{Q}}\right|=3.22 \mathrm{~mm} / \mathrm{s}$ ) are consistent with the formation of an $\mathrm{S}=1$ trigonal bipyramidal $\mathrm{Fe}^{\mathrm{II}}$-CO complex following internal electron transfer (Supplementary Table 3). ${ }^{52}$ In contrast to the well-defined reactivity of 3 , reactions of CO with synthetic, high spin iron(II/III) clusters typically result in cluster fragmentation and the formation of reduced, low spin iron carbonyl clusters, ${ }^{23-24}$ further illustrating the advantages of employing robust ligand scaffolds to interrogate chemistry relevant to nitrogenase..$^{29,36}$

Reversible Co Binding Across Four Redox States. Encouraged by the reactivity of $\mathbf{3}$ with $\mathrm{CO}$, we investigated the dependence of CO binding on the redox state of the cluster. Remarkably, binding of CO remains reversible for 4-6. Cooling solutions of $\mathbf{4}$ in dichloromethane- $d_{2}$ under an atmosphere of CO affords 4-CO (Supplementary Fig. 31), an assignment confirmed by the observation of a single $\mathrm{CO}$ stretching frequency $\left(v_{\text {co }}=1966 \mathrm{~cm}^{-1}\right)$ in its IR spectrum (CO-saturated dichloromethane at 195 K, Figure 7c). Oxidation of 4 with $\left[\mathrm{N}\left(\mathrm{C}_{6} \mathrm{H}_{4} \mathrm{Br}-4\right)_{3}\right]$ [OTf] in dichloromethane- $d_{2}$ affords the all-ferric cluster [ $\left.\mathrm{LFe}_{3} \mathrm{O}(\mathrm{PhIm})_{3} \mathrm{Fe}\right][\mathrm{OTf}]_{4}(7)$, whose ${ }^{1} \mathrm{H}-\mathrm{NMR}$ (Supplementary Fig. 44) and UV-Vis (Supplementary Fig. 20) spectral features are identical under $\mathrm{N}_{2}$ or $\mathrm{CO}$, suggesting that at least one $\mathrm{Fe}^{\mathrm{II}}$ center is necessary for CO binding.

Under an atmosphere of $\mathrm{CO}, \mathbf{5}$ converts predominately to [LFe $\left.{ }_{3} \mathrm{O}(\mathrm{PhIm})_{3} \mathrm{Fe}(\mathrm{CO})\right][\mathrm{OTf}]$ (5-CO) at room temperature based on IR ( $v_{\text {co }}=1916 \mathrm{~cm}^{-1}$, Supplementary Fig. 14) and ${ }^{1} \mathrm{H}-\mathrm{NMR}$ (Supplementary Fig. 12) spectroscopy. Further cooling converts 5-CO to 5-(CO) 2 (Supplementary Fig. 34), which exhibits diagnostic features at 1994 and $1944 \mathrm{~cm}^{-1}$ in its low temperature IR spectrum (CO-saturated dichloromethane at $195 \mathrm{~K}$, Figure $7 \mathrm{c}$ ). By ${ }^{1} \mathrm{H}-\mathrm{NMR}$ spectroscopy, heating 5-CO under $\mathrm{CO}$ in chlorobenzene- $d_{5}$ (Supplementary Fig. 41) or exposure to an atmosphere of $\mathrm{N}_{2}$ returns $\mathbf{5}$, demonstrating that binding of $\mathrm{CO}$ is reversible. Single crystals of 5-CO amenable to XRD were obtained from solutions of $\mathbf{5}$ under $\mathrm{CO}$ and confirm its identity as a monocarbonyl adduct featuring a trigonal bipyramidal coordination environment at Fe4 (Figure 3b).

Unfortunately, the insolubility of 6 precludes direct solution monitoring of its reactivity with $\mathrm{CO}$. However, changes in the ATR-IR spectrum following addition of an atmosphere of CO to a suspension of $\mathbf{6}$ in tetrahydrofuran supports the formation of both mono- (6-CO, $\left.v_{\mathrm{CO}}=1899 \mathrm{~cm}^{-1}\right)$ and dicarbonyl (6-(CO)2, $v_{\mathrm{co}}=1980$ and $\left.1891 \mathrm{~cm}^{-1}\right)$ adducts (Supplementary Fig. 17). The formation of these CO bound species is reversible; removing the $\mathrm{CO}$ atmosphere results in gradual loss of the Fe-CO stretching frequencies for both 6-CO and 6-(CO)2 and formation of an insoluble blue material with IR spectral features indicative of 6 .

TABLE 1. Summary of redox distribution assignments for $3-(\mathrm{CO})_{\mathrm{n}}-7-(\mathrm{CO}) \mathrm{n}$

\begin{tabular}{|c|c|c|}
\hline Complex & Distal Metals & Apical Metal \\
\hline$\left[\mathrm{LFe}_{3} \mathrm{O}(\mathrm{PhIm})_{3} \mathrm{Fe}\right][\mathrm{OTf}]_{4}(7)$ & {$\left[\mathrm{Fe}_{3}{ }_{3}^{\prime \prime \prime}\right]$} & $\mathrm{Fe}^{\prime \prime \prime}$ \\
\hline$\left[\mathrm{LFe}_{3} \mathrm{O}(\mathrm{Phlm})_{3} \mathrm{Fe}\right][\mathrm{OTf}]_{3}(\mathbf{4})$ & {$\left[\mathrm{Fe}^{\| \prime} \mathrm{Fe}_{2}{ }_{2}\right]$} & $\mathrm{Fe}^{\prime \prime \prime}$ \\
\hline$\left[\mathrm{LFe}_{3} \mathrm{O}(\mathrm{Phlm})_{3} \mathrm{Fe}\right][\mathrm{OTf}]_{2}(\mathbf{3})$ & {$\left[\mathrm{Fe}_{2}{ }_{2} \mathrm{Fe}^{\prime \prime \prime}\right]$} & $\mathrm{Fe}^{\prime \prime \prime \prime}$ \\
\hline$\left[\mathrm{LFe}_{3} \mathrm{O}(\mathrm{Phlm})_{3} \mathrm{Fe}\right][\mathrm{OTf}](\mathbf{5})$ & {$\left[\mathrm{Fe}_{2}{ }_{2} \mathrm{Fe}^{\prime \prime \prime}\right]$} & $\mathrm{Fe}^{\prime \prime}$ \\
\hline$\left[\mathrm{LFe}_{3} \mathrm{O}(\mathrm{Phlm})_{3} \mathrm{Fe}\right](6)$ & {$\left[\mathrm{Fe}_{3}\right]$} & $\mathrm{Fe}^{\prime \prime}$ \\
\hline$\left[\mathrm{LFe}_{3} \mathrm{O}(\mathrm{Phlm})_{3} \mathrm{Fe}(\mathrm{CO})\right][\mathrm{OTf}]_{2}(4-\mathrm{CO})$ & {$\left[\mathrm{Fe}_{3}^{\mathrm{III}}\right]$} & $\mathrm{Fe}^{\prime \prime}$ \\
\hline$\left[\mathrm{LFe}_{3} \mathrm{O}(\mathrm{PhIm})_{3} \mathrm{Fe}(\mathrm{CO})\right][\mathrm{OTf}]_{2}(\mathbf{3 - C O})$ & {$\left[\mathrm{Fe}{ }^{\prime \prime} \mathrm{Fe}_{2}\right]$} & $\mathrm{Fe}^{\prime \prime}$ \\
\hline$\left[\mathrm{LFe}_{3} \mathrm{O}(\mathrm{Phlm})_{3} \mathrm{Fe}(\mathrm{CO})\right][\mathrm{OTf}](5-\mathrm{CO})$ & {$\left[\mathrm{Fe}_{2}{ }_{2} \mathrm{Fe}^{\prime \prime \prime}\right]$} & $\mathrm{Fe}^{\prime \prime}$ \\
\hline$\left[\mathrm{LFe}_{3} \mathrm{O}(\mathrm{PhIm})_{3} \mathrm{Fe}(\mathrm{CO})\right](6-\mathrm{CO})$ & {$\left[\mathrm{Fe}_{3}{ }_{3}\right]$} & $\mathrm{Fe}^{\prime \prime}$ \\
\hline$\left[\mathrm{LFe}_{3} \mathrm{O}(\mathrm{PhIm})_{3} \mathrm{Fe}(\mathrm{CO})_{2}\right][\mathrm{OTf}]_{2}\left(3-(\mathrm{CO})_{2}\right)$ & {$\left[\mathrm{Fe}^{\mathrm{II}} \mathrm{Fe}_{2} \mathrm{III}\right]$} & $\mathrm{Fe}^{\prime \prime}$ \\
\hline$\left[\mathrm{LFe}_{3} \mathrm{O}(\mathrm{Phlm})_{3} \mathrm{Fe}(\mathrm{CO})_{2}\right][\mathrm{OTf}]\left(5-(\mathrm{CO})_{2}\right)$ & {$\left[\mathrm{Fe}_{2}{ }_{2} \mathrm{Fe}^{\prime \prime \prime}\right]$} & $\mathrm{Fe}^{\prime \prime}$ \\
\hline$\left[\mathrm{LFe}_{3} \mathrm{O}(\mathrm{Phlm})_{3} \mathrm{Fe}(\mathrm{CO})_{2}\right]\left(6-(\mathrm{CO})_{2}\right)$ & {$\left[\mathrm{Fe}_{3}\right]$} & $\mathrm{Fe}^{\prime \prime}$ \\
\hline
\end{tabular}

For the monocarbonyl complexes described herein, shifts in $v_{\text {co }}$ of only $20-30 \mathrm{~cm}^{-1}$ are observed per redox event (6CO: $1899 \mathrm{~cm}^{-1}$, 5-CO: $1916 \mathrm{~cm}^{-1}$, 3-CO: $1944 \mathrm{~cm}^{-1}$, 4-CO: $1966 \mathrm{~cm}^{-1}$, Figure $5 \mathrm{c}$ ). These shifts are similar in magnitude to those which arise from remote redox chemistry in related tetranuclear iron nitrosyl clusters ${ }^{39,41}$ and are significantly smaller than expected for redox chemistry centered at the Fe-CO unit ( $\sim 100 \mathrm{~cm}^{-1}$ per redox event). ${ }^{48-49,53-54}$ Moreover, the observed Fe-CO stretching frequencies are within the range reported for other trigonal bipyramidal Fe ${ }^{\mathrm{II}}$ monocarbonyl complexes (see Supplementary Table 3). Combined with the observation of a change in the core redox level of 3 by Mössbauer spectroscopy, ${ }^{55}$ these results suggest an $\mathrm{Fe}^{\mathrm{II}}$ CO assignment across the redox series (3-CO to 6-CO). This implies that coordination of $\mathrm{CO}$ induces an internal electron transfer from one of the distal $\mathrm{Fe}^{\mathrm{II}}$ centers to the apical Fe $\mathrm{FII}^{\mathrm{III}}$ site in both 3 and $\mathbf{4}$. Ligand-induced redox reorganizations (LIRR) related to those observed for $\mathbf{3}$ and $\mathbf{4}$ have been reported for monometallic compounds featuring redox active supporting ligands, ${ }^{56-59}$ as well as complexes with pendant ferrocenyl substituents. ${ }^{60-61}$ Notwithstanding, we are not aware of precedence for a reversible, internal electron transfer involving metal centers within a multinuclear cluster which is induced by small molecule binding. Changes in the identity of an ancillary ligand (DMF, MeCN, or - $\mathrm{CN}$ ) have been shown to modulate the extent of valence delocaliza- 
tion in a series of hexairon clusters. ${ }^{62}$ However, the site-differentiated nature of the clusters examined here allows us to distinguish the effects of $\mathrm{CO}$ binding on the electronic properties of the binding site from those on remote metal centers.

CO Binding Energetics. In order to quantify the effect of redox chemistry on the affinity of 3-6 for $\mathrm{CO}$, we evaluated their $\mathrm{CO}$ binding energetics by ${ }^{1} \mathrm{H}-\mathrm{NMR}$ spectroscopy, which facilitated accurate identification of speciation in the reaction mixtures. ${ }^{63}$ At $303 \mathrm{~K}$, the $\mathrm{CO}$ binding constant for $\mathbf{3}$ $\left(K_{1}(3)=0.15 \mathrm{~atm}^{-1}\right.$, dichloromethane- $d_{2}, P_{\mathrm{CO}}=1 \mathrm{~atm}$. $)$ is at least $10^{3}$-fold lower than for most $\mathrm{Fe}^{\mathrm{II}}$ complexes (Table 2),64-66 though a sterically encumbered, trigonal monopyrimidal $\mathrm{Fe}^{\mathrm{II}}$ complex with a similar affinity for $\mathrm{CO}\left(K_{298 \mathrm{~K}}=\right.$ $6.9 \mathrm{~atm}^{-1}$ ) has been reported. ${ }^{67}$ The thermodynamic parameters associated with the formation of 3-CO $(\Delta H=-13.6(8)$ $\left.\mathrm{kcal} \cdot \mathrm{mol}^{-1}, \Delta S=-48(3) \mathrm{cal} \cdot \mathrm{mol}^{-1} \cdot \mathrm{K}^{-1}\right)$ suggest that this low $\mathrm{CO}$ affinity derives from an unusually large entropic penalty, which we attribute to loss of rotational freedom in the flanking aryl substituents upon CO binding. While a complete study on the energetics of forming 5-CO in dichloromethane (b.p. $=39.6{ }^{\circ} \mathrm{C}$ ) was not possible due to temperature constraints, at $303 \mathrm{~K}$ the affinity of the apical $\mathrm{Fe}^{\mathrm{II}}$ of $\mathbf{5}$ for $\mathrm{CO}$ $\left(K_{1}(5)\right)$ was determined to be $59 \mathrm{~atm}^{-1}$, an enhancement of only $\sim 400$-fold $\left(\Delta \Delta G_{303 \mathrm{~K}} \sim 3.6 \mathrm{kcal} \cdot \mathrm{mol}^{-1}\right)$ relative to 3 , which features an apical Fe ${ }^{\text {III }}$.

In contrast to the relatively small difference in the $\mathrm{CO}$ affinities of $\mathbf{3}$ and $\mathbf{5}$ ( $\sim 400$-fold), significantly larger enhancements ( $>10^{5}$-fold) in binding affinities have previously been reported to accompany $1 \mathrm{e}^{-}$redox chemistry (Table 2 ). For example, reduction of a square planar iron tetraphosphine complex from iron(II) to iron(I) and then to iron(0) results in successive $\sim 10^{22}$-fold and $10^{5}$-fold enhancements in its affinity for $\mathrm{N}_{2} \cdot{ }^{68}$ Reduction of a low spin $\left(\mathrm{N}_{2}\right) \mathrm{Fe}^{\mathrm{II}}(\mu-\mathrm{H})_{2} \mathrm{Fe}^{\mathrm{II}}$ complex to its valence-delocalized $\left(\mathrm{N}_{2}\right) \mathrm{Fe}^{\mathrm{I}}(\mu-\mathrm{H})_{2} \mathrm{Fe}^{\mathrm{II}}$ congener results in a $10^{6}$-fold enhancement in its affinity for a second molecule of $\mathrm{N}_{2 .}{ }^{35}$ Notably, computational studies revealed that the SOMO of both $\left(\mathrm{N}_{2}\right) \mathrm{Fe}^{\mathrm{I}}(\mu-\mathrm{H})_{2} \mathrm{Fe}^{\mathrm{II}}$ and $\left(\mathrm{N}_{2}\right) \mathrm{Fe}^{\mathrm{I}}(\mu-\mathrm{H})_{2} \mathrm{Fe}^{\mathrm{II}}\left(\mathrm{N}_{2}\right)$ complexes are valence-delocalized, suggesting that minimal redox reorganization accompanies $\mathrm{N}_{2}$ binding, and the large effect on binding is due to the formal difference in oxidation state at the $\mathrm{N}_{2}$ binding site.

The small influence which reduction of $\mathbf{3}$ to $\mathbf{5}$ has on the CO binding energetics seems inconsistent with the low affinity $\mathrm{Fe}^{\mathrm{III}}$ typically exhibits toward $\mathrm{CO}^{50}$ and the large changes in binding affinity seen in other systems upon $1 \mathrm{e}^{-}$ reduction. We propose instead that the internal electron transfer ( $i$-ET) which accompanies coordination of CO to 3 facilitates this otherwise unfavorable binding event. From this perspective, $\mathbf{3}$ contains a masked apical Fe ${ }^{\mathrm{II}}$ site whose affinity for $\mathrm{CO}$ is modulated relative to $\mathbf{5}$ by two terms, one accounting for the energetic cost of redox reorganization and the other for the effect of changes in redox states of the remote metals (Figure 8). Although our data for these and related clusters ${ }^{39-41,69-70}$ is most consistent with a valencelocalized assignment, an analogous scheme can be constructed for a valence-delocalized system, where the internal electron transfer ( $i$-ET) term is replaced by a term accounting for the energetic penalty of trapping an electron at $\mathrm{Fe} 4$, assuming the CO bound product is valence-localized.
Despite the simplicity of this thermodynamic model, it adequately accounts for trends in the energetics of $\mathrm{CO}$ binding in 3-5. The difference in enthalpy $(\Delta \Delta H)$ for the second CO binding event in $\mathbf{3}$ and $\mathbf{5}$, the formation of 3-(CO) 2 and 5(CO) 2 , respectively, is only $0.9(6) \mathrm{kcal} \cdot \mathrm{mol}^{-1}$. This small $\Delta \Delta H$ reflects the relatively small influence that the redox states of the remote metal sites have on $\mathrm{CO}$ binding in these high spin, valence-localized iron clusters in the absence of redox reorganization. In contrast, the first $\mathrm{CO}$ binding event for $\mathbf{3}$ and 5, the formation of 3-CO and 5-CO, respectively, has a larger $\Delta \Delta H\left(3.6 \mathrm{kcal} \cdot \mathrm{mol}^{-1}\right)$. Assuming that changes in the redox state of the remote metals have an effect on $\mathrm{CO}$ binding similar to that observed in the dicarbonyl series $(\sim 1$ $\mathrm{kcal} \cdot \mathrm{mol}^{-1}$ ), the redox reorganization penalty must be on the order of $2.6(6) \mathrm{kcal} \cdot \mathrm{mol}^{-1}(R R E=-\mathrm{nF} \Delta E, \Delta E \sim 110 \mathrm{mV})$.

TABLE 2. Thermodynamics of diatomic binding for 3-5 in dichloromethane and selected reference compounds.

\begin{tabular}{ccccc} 
Complex & Ligand & $K_{303 \mathrm{~K}}\left(\mathrm{~atm}^{-1}\right)$ & $\Delta H\left(\mathrm{kcal} \mathrm{mol}^{-1}\right) \Delta S\left(\mathrm{cal} \mathrm{mol}^{-1} \mathrm{~K}^{-1}\right)$ \\
\hline chelated protoheme $^{\mathrm{a}}$ & $\mathrm{CO}$ & $1.6 \times 10^{6}$ & -17.5 & -34 \\
$\mathrm{Fe}^{\prime \prime}(\mathrm{TPP})\left(1,2-\mathrm{Me}_{2} \mathrm{Im}\right)^{\mathrm{a}}$ & $\mathrm{CO}$ & $3.4 \times 10^{3}$ & -12.8 & -26.1 \\
$\mathrm{Fe}^{\prime \prime}(\mathrm{PocPiv})\left(1,2-\mathrm{Me}_{2} \mathrm{Im}\right)^{\mathrm{a}}$ & $\mathrm{CO}$ & $8.2 \times 10^{3}$ & -13.9 & -28 \\
$\mathrm{~K}\left[\mathrm{~N}\left(\mathrm{CH}_{2} \mathrm{C}(\mathrm{O}) \mathrm{N}^{\prime} \mathrm{Pr}\right)_{3} \mathrm{Fe}^{\prime \prime}\right]^{\mathrm{b}}$ & $\mathrm{CO}$ & 6.9 & --- & --- \\
\hline$\left[\mathrm{Fe}^{\prime \prime}\left(\mathrm{P}_{4} \mathrm{~N}_{2}\right)\right]\left[\mathrm{B}\left(\mathrm{C}_{6} \mathrm{~F}_{5}\right)_{4}\right]_{2}{ }^{\mathrm{c}}$ & $\mathrm{N}_{2}$ & $<4 \times 10^{-23}$ & --- & --- \\
{$\left[\mathrm{Fe}^{\prime}\left(\mathrm{P}_{4} \mathrm{~N}_{2}\right)\right]\left[\mathrm{B}\left(\mathrm{C}_{6} \mathrm{~F}_{5}\right)_{4}\right]^{\mathrm{c}}$} & $\mathrm{N}_{2}$ & 0.4 & -6.5 & -23.4 \\
{$\left[\mathrm{Fe}^{0}\left(\mathrm{P}_{4} \mathrm{~N}_{2}\right)\right]^{\mathrm{c}}$} & $\mathrm{N}_{2}$ & $\sim 4 \times 10^{4}$ & --- & --- \\
\hline$\left[\left(\mathrm{N}_{2}\right) \mathrm{Fe}^{\prime \prime}(\mu-\mathrm{H})_{2} \mathrm{Fe}^{\prime \prime}\right]^{\mathrm{d}}$ & $\mathrm{N}_{2}$ & $1.1 \mathrm{M}^{-1}$ & -9 & -30 \\
{$\left[\left(\mathrm{~N}_{2}\right) \mathrm{Fe}^{1.5}(\mu-\mathrm{H})_{2} \mathrm{Fe}^{1.5}\right]^{\mathrm{d}}$} & $\mathrm{N}_{2}$ & $\sim 2.9 \times 10^{6} \mathrm{M}^{-1}$ & --- & --- \\
\hline $\mathbf{4}$ & $\mathrm{CO}$ & $0.2^{\mathrm{e}}$ & -12.1 & -47 \\
$\mathbf{3}$ & $\mathrm{CO}$ & 0.2 & -13.6 & -48 \\
$\mathbf{5}$ & $\mathrm{CO}$ & 59 & $-17.2^{\mathrm{f}}$ & --- \\
\hline $\mathbf{3 - C O}$ & $\mathrm{CO}$ & $0.1^{\mathrm{e}}$ & -8.3 & $-32^{\mathrm{g}}$ \\
$\mathbf{5 - C O}$ & $\mathrm{CO}$ & $0.2^{\mathrm{e}}$ & -9.2 & $-34^{\mathrm{g}}$
\end{tabular}

Standard state: $1 \mathrm{~atm}$. CO unless noted otherwise. a. Data taken from ref. $64, K 303 \mathrm{~K}$ calculated from $\ln K=\Delta S / \mathrm{R}-\Delta H / \mathrm{RT}$. b. Data taken from ref. 67. K measured at 298 K. c. Data taken from ref. 68. $K$ measured directly or determined electrochemically at 298 K. d. Data taken from ref. 35. Standard state: 1 M CO. K (M1) measured directly or determined electrochemically at $298 \mathrm{~K}$. e. Calculated at $303 \mathrm{~K}$ from $\ln K=\Delta S / \mathrm{R}-\Delta H / \mathrm{RT}$. See Supplementary Tables 6-7 for measured values. f. Estimated from $\Delta \Delta G$ $=3.6 \mathrm{kcal} \cdot \mathrm{mol}^{-1}$ assuming $\Delta \Delta S \sim 0 \mathrm{cal} \cdot \mathrm{mol}^{-1} \cdot \mathrm{K}^{-1}$ for 3 vs. 5 . g. The smaller entropic penalty for the formation of the dicarbonyl adducts suggests that $\mathrm{CO}$ binding is cooperative, perhaps due to rotational "locking" of the aryl substituents upon formation of the corresponding monocarbonyl adducts. Note, independent measurements for $\mathbf{3}$ in acetone- $d_{6}$ and $\mathbf{5}$ in chlorobenzene- $d_{5}$ confirm the observed trends. Despite a 1500-fold difference in the CO affinity of $\mathbf{5}$ compared to $\mathbf{3}$ at $298 \mathrm{~K}$, the CO binding constants of 5-CO and 3-CO differ by a factor of only 1.6. For additional details, see the Supporting Information.

As in 3, the formation of 4-CO must involve a redox reorganization and hence, the difference in $\Delta H$ for $\mathrm{CO}$ binding between them should reflect only the remote redox effect if the above model is correct. The observation of a $\Delta \Delta H$ of $\sim 1.5$ $\mathrm{kcal} / \mathrm{mol}$ for the formation of 3-CO and 4-CO is thus in agreement with this model. This further implies that the redox reorganization in $\mathbf{4}$ has a similar energetic penalty $(\Delta \Delta E$ 
$\sim 0$ ) despite the more oxidized basal triiron core. While oxidation of $\mathbf{3}$ to $\mathbf{4}$ does elongate the Fe3-01 distance from

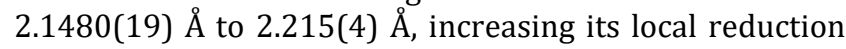
potential, the influence of this structural rearrangement on $\Delta E$ must be largely levelled by a concomitant increase in the Fe4-01 distance from 1.8128(19) to 1.855(4) Å (Supplementary Table 4). Given the valence-localized nature of these clusters, it is not surprising that the local redox potentials of the core $\mathrm{Fe}^{\mathrm{II}}$ sites (relative to the apical $\mathrm{Fe}^{\mathrm{III}}$ center) remain mostly invariant to cluster redox chemistry. As such, the redox reorganization energy associated with internal electron transfer $\left(R R E \sim 2.6 \mathrm{kcal} \cdot \mathrm{mol}^{-1}\right)$ is not significantly perturbed by redox state. This levelling of $\Delta E$ in valence-localized clusters leads us to the conclusion that the most drastic differences in ligand binding affinities between oxidized and reduced species will be observed at the point where redox reorganization ceases to be required, as observed for 3-5.

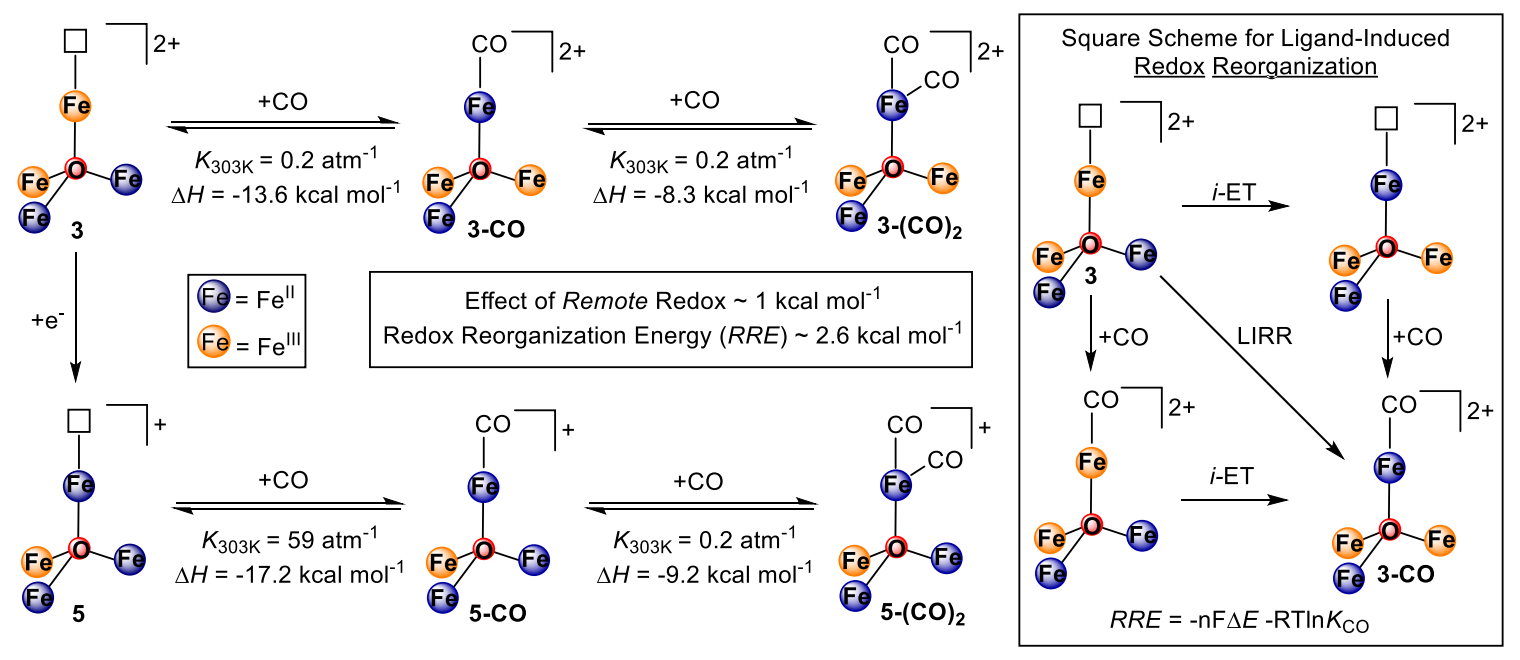

In summary, for high spin, valence-localized iron clusters such as those described herein, small enhancements (at most $\sim 400$-fold) in the affinity for $\pi$-acids arise from pure redox chemistry, despite a notable effect on the degree of CO activation $\left(67 \mathrm{~cm}^{-1}\right.$ over three redox events). Deconvoluting the effect of redox at specific sites within the cluster, we demonstrate that electron-loading at metal centers $r e$ mote from the substrate binding site has a relatively small influence on the CO binding energetics $\left(\sim 1 \mathrm{kcal} \cdot \mathrm{mol}^{-1}\right)$. Nonetheless, availability of reducing equivalents and internal electron transfers from these remote metal sites facilitate binding of $\pi$-acids at the apical $\mathrm{Fe}^{\mathrm{III}}$ center due to the relatively small energetic penalty arising from redox reorganization (RRE $\left.\sim 2.6 \mathrm{kcal} \cdot \mathrm{mol}^{-1}\right)$. The ease with which these valence-localized, high spin iron clusters redistribute electrons in response to ligand binding provides insight into redox-dependent binding of $\mathrm{N}_{2}$ and $\mathrm{CO}$ by FeMoco, especially in light of a recent report which suggests that substrate binding interactions may occur on an oxidized edge of the cofactor. ${ }^{19}$

FIGURE 8. Thermodynamics of ligand-induced redox reorganization. The difference in the CO binding enthalpy for 3-CO and 5-Co $\left(\Delta \Delta H \sim 1 \mathrm{kcal} \cdot \mathrm{mol}^{-1}\right)$ corresponds to the effect of remote redox chemistry on the CO affinity of the apical Fe $\mathrm{F}^{\mathrm{II}}$ center. A similar value is obtained comparing 3 and $4\left(\Delta \Delta H \sim 1.5 \mathrm{kcal} \cdot \mathrm{mol}^{-1}\right)$. The larger difference in the enthalpy of CO binding to $3 \mathrm{vs}$. $5(\Delta \Delta H \sim 3.6$ $\mathrm{kcal} \cdot \mathrm{mol}^{-1}$ ) arises from the energetic penalty associated with internal electron transfer in 3 . From this, we can estimate a redox reorganization energy (RRE) of $\sim 2.6 \mathrm{kcal} \cdot \mathrm{mol}^{-1}$. Right: Thermodynamic square scheme for ligand-induced redox organization (LIRR). Note, electron transfer is coupled to structural rearrangements, especially within the $\mathrm{Fe}_{4}\left(\mu_{4}-0\right)$ motif (Supplementary Table 4), such that the redox sites and their relative potentials are not fully independent.

\section{ASSOCIATED CONTENT}

Synthetic procedures, characterization data and crystal structures, spectroscopic and electrochemical results, $\mathrm{CO}$ reactivity studies. This material is available free of charge via the Internet at http://pubs.acs.org.

\section{AUTHOR INFORMATION}

\section{Corresponding Author}

*agapie@caltech.edu

\section{ACKNOWLEDGMENT}

This research was supported by the NIH (R01-GM102687B). T.A. is grateful for a Dreyfus fellowship. C.H.A. and M.J.C. are grateful for NSF Graduate Research Fellowships. We thank Michael Takase and Lawrence Henling for assistance with crystallography, Heui Boom Lee for assistance with SQUID magnetometry, and Paul Oyala assistance with EPR spectroscopy (NSF1531940 for EPR instrumentation). We thank Graham de Ruiter, Joshua Buss, and Christopher Reed for insightful discussions.

\section{REFERENCES}

(1) Burgess, B. K.; Lowe, D. J. Chem. Rev. 1996, 96, 29833012.

(2) Hu, Y.; Ribbe, M. W. Angew. Chem. Int. Ed. 2016, 55, 82168226.

(3) Spatzal, T.; Aksoyoglu, M.; Zhang, L.; Andrade, S. L. A.; Schleicher, E.; Weber, S.; Rees, D. C.; Einsle, O. Science 2011, 334, 940-940. 
(4) Lancaster, K. M.; Roemelt, M.; Ettenhuber, P.; Hu, Y.; Ribbe, M. W.; Neese, F.; Bergmann, U.; DeBeer, S. Science 2011, 334, 974-977.

(5) Hoffman, B. M.; Lukoyanov, D.; Yang, Z.-Y.; Dean, D. R.; Seefeldt, L. C. Chem. Rev. 2014, 114, 4041-4062.

(6) Pickett, C. J.; Vincent, K. A.; Ibrahim, S. K.; Gormal, C. A.; Smith, B. E.; Best, S. P. Chem. Eur. J. 2003, 9, 76-87.

(7) Yan, L.; Pelmenschikov, V.; Dapper, C. H.; Scott, A. D.; Newton, W. E.; Cramer, S. P. Chem. Eur. J. 2012, 18, 16349-16357.

(8) Paengnakorn, P.; Ash, P. A.; Shaw, S.; Danyal, K.; Chen, T.; Dean, D. R.; Seefeldt, L. C.; Vincent, K. A. Chem. Sci. 2017, 8, 15001505.

(9) Lee, H.-I.; Cameron, L. M.; Hales, B. J.; Hoffman, B. M. J. Am. Chem. Soc. 1997, 119, 10121-10126.

(10) Tolland, J. D.; Thorneley, R. N. F. Biochemistry 2005, 44, 9520-9527.

(11) Scott, A. D.; Pelmenschikov, V.; Guo, Y.; Yan, L.; Wang, H.; George, S. J.; Dapper, C. H.; Newton, W. E.; Yoda, Y.; Tanaka, Y.; Cramer, S. P. J. Am. Chem. Soc. 2014, 136, 15942-15954.

(12) Spatzal, T.; Perez, K. A.; Einsle, O.; Howard, J. B.; Rees, D. C. Science 2014, 345, 1620-1623.

(13) Yang, Z.-Y.; Seefeldt, L. C.; Dean, D. R.; Cramer, S. P.; George, S. J. Angew. Chem. Int. Ed. 2011, 50, 272-275.

(14) Lee, H.-I.; Igarashi, R. Y.; Laryukhin, M.; Doan, P. E.; Dos Santos, P. C.; Dean, D. R.; Seefeldt, L. C.; Hoffman, B. M. J. Am. Chem. Soc. 2004, 126, 9563-9569.

(15) Benton, P. M. C.; Laryukhin, M.; Mayer, S. M.; Hoffman, B. M.; Dean, D. R.; Seefeldt, L. C. Biochemistry 2003, 42, 9102-9109.

(16) George, S. J.; Barney, B. M.; Mitra, D.; Igarashi, R. Y.; Guo, Y.; Dean, D. R.; Cramer, S. P.; Seefeldt, L. C. J. Inorg. Biochem. 2012 $112,85-92$

(17) Sarma, R.; Barney, B. M.; Keable, S.; Dean, D. R.; Seefeldt, L. C.; Peters, J. W. J. Inorg. Biochem. 2010, 104, 385-389.

(18) Dos Santos, P. C.; Igarashi, R. Y.; Lee, H.-I.; Hoffman, B. M.; Seefeldt, L. C.; Dean, D. R. Acc. Chem. Res. 2005, 38, 208-214.

(19) Spatzal, T.; Schlesier, J.; Burger, E.-M.; Sippel, D.; Zhang L.; Andrade, S. L. A.; Rees, D. C.; Einsle, O. Nat. Commun. 2016, 7 10902.

(20) Venkateswara Rao, P.; Holm, R. H. Chem. Rev. 2004, 104, 527-560.

(21) Tanifuji, K.; Sickerman, N.; Lee, C. C.; Nagasawa, T.; Miyazaki, K.; Ohki, Y.; Tatsumi, K.; Hu, Y.; Ribbe, M. W. Angew. Chem. Int. Ed. 2016, 55, 15633-15636.

(22) Ohta, S.; Ohki, Y.; Hashimoto, T.; Cramer, R. E.; Tatsumi, K. Inorg. Chem. 2012, 51, 11217-11219.

(23) Al-Ani, F. T.; Hughes, D. L.; Pickett, C. J. J. Organomet. Chem. 1986, 307, C31-C34.

(24) Han, J.; Coucouvanis, D. Dalton Trans. 2005, 1234-1240.

(25) Eames, E. V.; Betley, T. A. Inorg. Chem. 2012, 51, 10274 10278.

(26) Kuppuswamy, S.; Wofford, J. D.; Joseph, C.; Xie, Z.-L.; Ali, A. K.; Lynch, V. M.; Lindahl, P. A.; Rose, M. J. Inorg. Chem. 2017, 56, 5998-6012.

(27) Sickerman, N. S.; Tanifuji, K.; Lee, C. C.; Ohki, Y.; Tatsumi, K.; Ribbe, M. W.; Hu, Y. J. Am. Chem. Soc. 2017, 139, 603-606.

(28) Ohki, Y.; Araki, Y.; Tada, M.; Sakai, Y. Chem. Eur. J. 2017, $23,13240-13248$.

(29) Anderton, K. J.; Knight, B. J.; Rheingold, A. L.; Abboud, K. A.; Garcia-Serres, R.; Murray, L. J. Chem. Sci. 2017, 8, 4123-4129.

(30) MacLeod, K. C.; McWilliams, S. F.; Mercado, B. Q.; Holland, P. L. Chem. Sci. 2016, 7, 5736-5746.

(31) Bellows, S. M.; Arnet, N. A.; Gurubasavaraj, P. M.; Brennessel, W. W.; Bill, E.; Cundari, T. R.; Holland, P. L. J. Am. Chem. Soc. 2016, 138, 12112-12123.

(32) Lee, Y.; Sloane, F. T.; Blondin, G.; Abboud, K. A.; GarcíaSerres, R.; Murray, L. J. Angew. Chem. Int. Ed. 2015, 54, 1499-1503.

(33) Creutz, S. E.; Peters, J. C. J. Am. Chem. Soc. 2015, 137 7310-7313.
(34) Arnet, N. A.; Dugan, T. R.; Menges, F. S.; Mercado, B. Q.; Brennessel, W. W.; Bill, E.; Johnson, M. A.; Holland, P. L. J. Am. Chem. Soc. 2015, 137, 13220-13223.

(35) Rittle, J.; McCrory, C. C. L.; Peters, J. C. J. Am. Chem. Soc 2014, 136, 13853-13862.

(36) Powers, T. M.; Betley, T. A. J. Am. Chem. Soc. 2013, 135, 12289-12296.

(37) Li, Y.; Li, Y.; Wang, B.; Luo, Y.; Yang, D.; Tong, P.; Zhao, J.; Luo, L.; Zhou, Y.; Chen, S.; Cheng, F.; Qu, J. Nat. Chem. 2013, 5, 320.

(38) Rodriguez, M. M.; Bill, E.; Brennessel, W. W.; Holland, P. L. Science 2011, 334, 780-783.

(39) Reed, C. J.; Agapie, T. Inorg. Chem. 2017, 56, 1336013367.

(40) de Ruiter, G.; Carsch, K. M.; Gul, S.; Chatterjee, R.; Thompson, N. B.; Takase, M. K.; Yano, J.; Agapie, T. Angew. Chem Int. Ed. 2017, 56, 4772-4776.

(41) de Ruiter, G.; Thompson, N. B.; Lionetti, D.; Agapie, T. J. Am. Chem. Soc. 2015, 137, 14094-14106.

(42) Tsui, E. Y.; Kanady, J. S.; Day, M. W.; Agapie, T. Chem. Commun. 2011, 47, 4189-4191.

(43) In this and all subsequent figures, we have chosen to represent bonding within the imidazolate bridging ligands with a delocalized N-C-N $\pi$ system. We prefer this representation based on the structural features of 3-5. The presence of delocalized N-C$\mathrm{N} \pi$ bonding is evidenced by the planarity of the imidazolate rings, by a sum of the angles around the aryl-substituted nitrogens near 360 degrees, and by the similarity of the two $\mathrm{C}-\mathrm{N}$ bond lengths within each respective ring.

(44) Due to the insolubility of $\mathbf{6}$, we are unable to fully characterize this material by standard solution- and solid-state techniques. However, in addition to the Mossbauer spectrum, we note that the blue color of $\mathbf{6}$ is characteristic of the all-ferrous redox state of the analogous pyrazolate bridged clusters (see ref. 41). Also, re-oxidation of this materical with $\left[\mathrm{Cp}_{2} \mathrm{Co}\right][\mathrm{OTf}]$ cleanly returns 5, suggesting that $\mathbf{6}$ is not a decomposition product. Moreover, the reactivity of $\mathbf{6}$ with $\mathrm{CO}$ and the electronic properties of its $\mathrm{CO}$ adducts are consistent with its assignment as $\left[\mathrm{LFe}_{3} \mathrm{O}(\mathrm{PhIm})_{3} \mathrm{Fe}\right]$.

(45) Münck, E.; Ksurerus, K.; Hendrich, M. P. In Methods Enzymol.; Academic Press: Cambridge, 1993.

(46) Therien, M. J.; Trogler, W. C. J. Am. Chem. Soc. 1987, 109, 5127-5133.

(47) Etzenhouser, B. A.; Cavanaugh, M. D.; Spurgeon, H. N.; Sponsler, M. B. J. Am. Chem. Soc. 1994, 116, 2221-2222.

(48) Hsu, H.-F.; Koch, S. A.; Popescu, C. V.; Münck, E. J. Am. Chem. Soc. 1997, 119, 8371-8372.

(49) Nakae, T.; Hirotsu, M.; Aono, S.; Nakajima, H. Dalton Trans. 2016, 45, 16153-16156.

(50) Benito-Garagorri, D.; Lagoja, I.; Veiros, L. F.; Kirchner, K A. Dalton Trans. 2011, 40, 4778-4792.

(51) In an effort to obtain additional information about the electronic structure of 3-CO, we have measured the parallel and perpendicular mode EPR spectra (at $5 \mathrm{~K}$ ) upon flash quenching samples of $\mathbf{3}$ prepared at various temperatures under $\mathrm{CO}$. Unfortunately, the only spectral change observed is the loss of the sharp EPR feature associated with 3; no new features are observed. The instability of 3-(CO)n toward CO loss precludes a study of its magnetic properties by SQUID magnetometry.

(52) The simulation of the spectrum of 3-CO presented in the text is supported by our IR spectroscopic data and is consistent with the findings of our ${ }^{1} \mathrm{H}-\mathrm{NMR}$ experiments. For alternative simulations that were considered, see the Supporting Information.

(53) Lee, Y.; Peters, J. C. J. Am. Chem. Soc. 2011, 133, 44384446.

(54) Rittle, J.; Peters, J. C. Proc. Natl. Acad. Sci. U. S. A. 2013 110, 15898-15903.

(55) Unfortunately, we are unable to generate 4-CO in nonchlorinated solvents. The trication $\mathbf{4}$ decomposes rapidly via 
reduction to 3 in the presence of polar, coordinating solvents such as acetone or acetonitrile. Chlorinated solvents cannot be used for frozen solution Mössbauer spectroscopy due to the strong absorption of $\gamma$ rays by heavier atoms such as $\mathrm{Cl}$.

(56) Gagne, R. R.; Ingle, D. M. J. Am. Chem. Soc. 1980, 102, 1444-1446.

(57) Gagne, R. R.; Ingle, D. M. Inorg. Chem. 1981, 20, 420-425.

(58) Lewis, J.; Schroder, M. J. Chem. Soc., Dalton Trans. 1982, 1085-1089.

(59) Sullivan, E. P.; Strauss, S. H. Inorg. Chem. 1989, 28, 30933095.

(60) Kourkine, I. V.; Slone, C. S.; Mirkin, C. A.; Liable-Sands, L. M.; Rheingold, A. L. Inorg. Chem. 1999, 38, 2758-2759.

(61) Camara, J. M.; Rauchfuss, T. B. Nat. Chem. 2011, 4, 26.

(62) Hernández Sánchez, R.; Zheng, S.-L.; Betley, T. A. J. Am. Chem. Soc. 2015, 137, 11126-11143.

(63) In addition to direct spectroscopic techniques, ligand binding affinities are commonly measured using electrochemical methods, especially where one or more of the binding constants is too large (or small) to measure directly. For our clusters, we are able to directly measure the $\mathrm{CO}$ binding constants in three redox states by ${ }^{1} \mathrm{H}-\mathrm{NMR}$ spectroscopy. We prefer these direct measurements for our system because they do not require any assumptions about cluster speciation at given temperature, concentration and pressure. By ${ }^{1} \mathrm{H}-\mathrm{NMR}$ spectroscopy, we can directly quantify the relevant species in the binding equilibria. We have measured the electrochemistry of $\mathbf{3}$ under CO (see the SI), but a full understanding of the changes in the electrochemical profile would require $\mathrm{CV}$ simulations involving two successive binding equilibria at each redox couple and assumptions about cluster speciation and relative rates of chemical and electron transfer events.

(64) David, S.; James, B. R.; Dolphin, D.; Traylor, T. G.; Lopez, M. A. J. Am. Chem. Soc. 1994, 116, 6-14.

(65) Suslick, K. S.; Reinert, T. J. J. Chem. Educ. 1985, 62, 974.

(66) Collman, J. P.; Brauman, J. I.; Iverson, B. L.; Sessler, J. L.; Morris, R. M.; Gibson, Q. H. J. Am. Chem. Soc. 1983, 105, 3052-3064.

(67) Ray, M.; Golombek, A. P.; Hendrich, M. P.; Young, V. G.; Borovik, A. S. J. Am. Chem. Soc. 1996, 118, 6084-6085.

(68) Prokopchuk, D. E.; Wiedner, E. S.; Walter, E. D.; Popescu, C. V.; Piro, N. A.; Kassel, W. S.; Bullock, R. M.; Mock, M. T. J. Am. Chem. Soc. 2017, 139, 9291-9301.

(69) de Ruiter, G.; Thompson, N. B.; Takase, M. K.; Agapie, T. J. Am. Chem. Soc. 2016, 138, 1486-1489.

(70) Herbert, D. E.; Lionetti, D.; Rittle, J.; Agapie, T. J. Am. Chem. Soc. 2013, 135, 19075-19078. 
TOC Graphic:

2

3

4

5

6

7

8

9

10

11

12

13

14

15

16

17

18

19

20

21

22

23

24

25

26

27

28

29

30

31

32

33

34

35

36

37

38

39

40

41

42

43

44

45

46

47

48

49

50

51

52

53

54

55

56

57

58

59

60

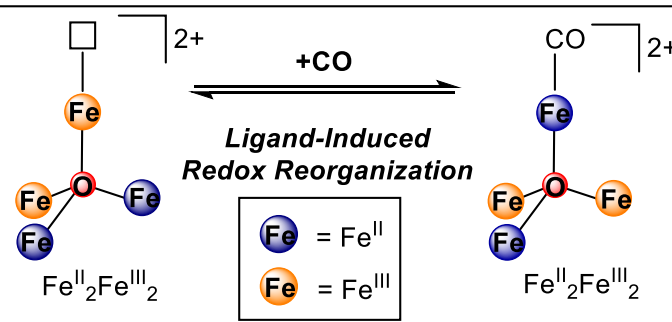

- Reversible binding in redox states $\mathrm{Fe}_{4}{ }_{4}$ through $\mathrm{Fe}^{\prime \prime} \mathrm{Fe}^{\prime \prime \prime}{ }_{3}$ - Facile redox reorganization allows $\mathrm{CO}$ binding at an oxidized cluster site 